\title{
Co-delivery of chemotherapeutic drugs and cell cycle regulatory agents using nanocarriers for cancer therapy
}

\author{
Ying Sun ${ }^{1 \dagger}$, Hao $\mathrm{Hu}^{1 \dagger}$, Xiaodong Jing ${ }^{1}$, Qingye Meng ${ }^{1}$, Bing $\mathrm{Yu}^{1,2}$, Hailin Cong ${ }^{1,2^{*}}$ and \\ Youqing Shen ${ }^{1,3}$
}

\begin{abstract}
Combination chemotherapy is widely exploited to overcome multidrug resistance (MDR) and enhance the therapeutic effect of anti-tumor agents clinically. The traditional combination regimens applied in clinical practice still suffer from various obstacles, such as inevitable side effects. Fortunately, the application of nanotechnology and the proposal of co-delivery systems make the combination therapy more effective. The occurrence, development, and metastasis of tumors are closely related to the cell cycle. The sensitivity of tumor cells to chemotherapeutic drugs can be improved with the cooperation of cell cycle regulators. In this review, the influence of the cell cycle on tumorigenesis and development is introduced briefly. The current strategies of combining chemotherapeutic drugs and cell cycle regulators through codelivery systems are discussed in detail. We also sketch the possibility of treating tumors mildly via artificially controlling the cell cycle and outline the challenges and perspectives about the improvement of co-delivery systems for cancer therapy.
\end{abstract}

Keywords: chemotherapy, cell cycle regulation, co-delivery system, combination therapy, cancer therapy

\section{INTRODUCTION}

In current cancer treatments, cancer cells often produce defensive measures against treatment strategies. The emergence of tumor chemotherapy resistance makes single chemotherapy unable to meet the requirements of clinical treatment. Therefore, combination of different chemotherapeutic drugs or treatments (e.g., chemo- therapy and radiotherapy) is operated to prevent the replication, invasion, and metastasis of cancer cells clinically [1]. Combination therapy strategies are of great significance for reducing side effects, overcoming multidrug resistance (MDR), reducing the dosage of each drug, and finally improving the therapeutic effect. However, due to different physical and chemical properties, different drugs have different pharmacokinetic properties in the body, resulting in different drug distribution ratios in tumor tissues. This will cause the combination of drugs to fail to achieve the expected efficacy. The application of nanotechnology in drug delivery has improved the pharmacokinetics of drugs [2]. Commonly used co-delivery nanocarriers include liposomes, micelles, polymer nanoparticles (NPs), exosomes, dendrimers, and magnetic NPs [3,4]. These carriers can improve the solubility, stability, and targeting of drugs, and combine the advantages of multiple cargoes to achieve a synergistic effect. For example, paclitaxel (PTX) and sunitinib (SUN) have a synergistic effect in the self-assembly co-delivery system, which provides a combination chemo-immunotherapy strategy to improve the therapeutic effect of triple-negative breast cancer (TNBC) [5]. The combined use of PTX/lapatinib (LAP) and cisplatin (CDDP)/metformin (ME) has also been proven to produce synergistic effects and improve the effectiveness of tumor treatment $[6,7]$.

Cell cycle regulation is important for cell proliferation, growth and damage repair. Abnormal tumor proliferation is related to abnormalities of the tumor cell cycle, signal

\footnotetext{
${ }^{1}$ Institute of Biomedical Materials and Engineering, College of Materials Science and Engineering, Qingdao University, Qingdao 266071, China

${ }^{2}$ Laboratory for New Fiber Materials and Modern Textile, Growing Base for State Key Laboratory, College of Chemistry and Chemical Engineering, Qingdao University, Qingdao 266071, China

${ }^{3}$ Center for Bionanoengineering and Key Laboratory of Biomass Chemical Engineering of Ministry of Education, College of Chemical and Biological Engineering, Zhejiang University, Hangzhou 310027, China

$\uparrow$ These authors contributed equally to the work.

* Corresponding author (email: hailincong@yahoo.com)
} 
transduction, and apoptosis pathways [8]. Chemotherapeutic drugs could be classified into cell cycle nonspecific agents (CCNSA) and cell cycle specific agents (CCSA) according to their effects on the cell cycle [9]. CCNSA, such as alkylating agents and anthracyclines, act on cells in all phases of the proliferating cell population, including cells in the G0 phase [10]. Alkylating agents can covalently bind to biological macromolecules in cells (such as DNA, RNA, and enzymes), making them inactive or damaged. Platinum-based drugs can also cause extensive DNA damage [11]. These injuries can be repaired through the nucleotide excision repair (NER), resulting in MDR [12]. CCSA mainly affects a certain phase of the cell cycle [13]. For example, antimetabolites have a significant impact on S-phase cells, and plant alkaloids mainly act on M-phase cell $[14,15]$. PTX can specifically act on the G2 and M phases of the cell cycle and inhibit the formation of spindle filaments. Thus, the division and proliferation of tumor cells would be prevented [16]. Tetramethylated hydroxydiethylene caused cell cycle arrest in $S$ phase and apoptosis by down-regulation of the cycling A1/cycling A2 expression and the rise of Bax/Bcl2 ratio in a p21-dependant pathway [17].

In the current study, regulating cell cycle for tumor therapy is mainly to control the expression of related genes and the activity of enzymes, proteins, or signaling factors in the cell [18]. As shown in Fig. 1, the strategies can be divided into two parts: (1) inhibition-by blocking cells at a certain phase to increase the sensitivity of CCSA; (2) promotion-by driving G0 tumor cells to re-enter the replication cycle and increase tumor sensitivity to chemo- therapy. For example, curcumin (CUR) modulates diverse transcription factors, inflammatory cytokines, enzymes, kinases, growth factors, receptors, and various other proteins. It can also regulate tumor cell growth via modulation of numerous cell signaling pathways and potentiates the effect of chemotherapeutic agents and radiation against cancer [19]. Some chemotherapeutic drugs work by blocking the cell cycle. Concato et al. [20] proved that $3,3^{\prime}, 5,5^{\prime}$-tetramethoxybiphenyl-4, $4^{\prime}$-diol (TMBP) has a strong cytotoxic effect on human nonsmall cell lung cancer (NSCLC) A549 cells and can cause mitochondrial dysfunction, induce cell G2/M phase arrest, and reduce cell survival rate. Zhang et al. [21] demonstrated that Asparanin A (AA) can be a possible functional food ingredient to cure endometrial cancer followed by clinical trials. AA inhibited the Ishikawa cell proliferation and caused cell morphology alteration and cell cycle arrest in G0/G1 phase. There are also studies that increase the sensitivity of tumor cells to chemotherapeutic drugs by speeding up the cell cycle [22-25]. Zhu et al. [26] found that LB1 (4-(3-carboxy-7-oxa-bicyclo [2.2.1] heptane-2-carbonyl) piperazine-1-carboxylic acid tertbutyl ester) could enhance the effect of cancer chemotherapy by driving quiescent cancer cells into the cell cycle and by blocking other replication checkpoints triggered by DNA damage through a significant inhibition effect of PP2A. De Jong et al. [27] reported that tyrosine kinase inhibitors MK-5108, LY2603618 and Volasertib can promote DNA-damaged cells into mitosis and increase the sensitivity of conventional chemotherapy. The combination of cell cycle regulation and che-

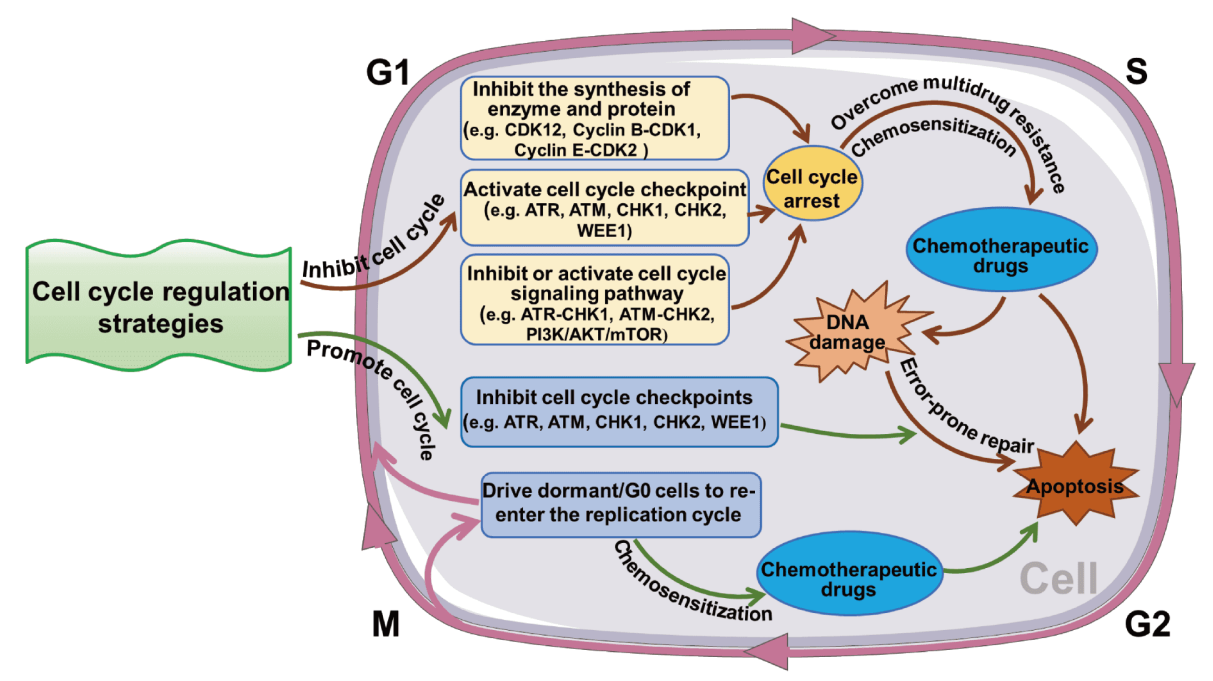

Figure 1 Combination strategies of chemotherapeutic drugs and cell cycle regulation. 
motherapy is of great significance for overcoming the obstacles encountered in chemotherapy alone and improving the efficacy of tumor therapy. Although many studies on this area have been proposed, few reviews on this field have been reported to date.

In this review, we first briefly introduce the impact of cell cycle on tumor tumorigenesis and development, as well as the mechanism of commonly used chemotherapeutic drugs. The collaborative strategies of cell cycle regulation and chemotherapy are discussed. Then we focus on the exemplary co-delivery systems used to implement the collaborative strategy for cancer therapy.

\section{CELL CYCLE REGULATION AND CHEMOTHERAPEUTIC DRUGS}

\section{Cell cycle and regulation}

The cell cycle is an ordered set of events that ultimately leads to cell growth and division. The cell cycle of eukaryotes can be divided into intermitotic and mitotic phases. The division phase provides material preparation for cell division and is divided into G1, S, and G2 phases. The division period is mainly the process of dividing cells into two separate parts, which is divided into prophase, metaphase, anaphase and telophase. After a period of division, the DNA and proteins of the cell are divided equally into two cells, completing the process of cell replication. Cells enter the G1 phase, during which RNA and protein are synthesized but no DNA is replicated. The start of DNA replication marks the transition from the G1 phase to the $S$ phase, and when DNA replication is complete, it means the end of the $S$ phase. In the $S$ phase, the amount of DNA is doubled. At this stage, the nucleus becomes larger, the protein accumulates, and the chromatin is concentrated, but there is no change in morphology. G0 phase is a special period in which the cells do not divide or proliferate temporarily, but can re-enter the cell cycle under proper stimulation. Cell division is orchestrated by a complex network of interactions between proteins, metabolism and microenvironment including several signaling pathways and mechanisms of control aiming to enable cell proliferation only in response to specific stimuli and under adequate conditions [28].

Cyclin-dependent kinases (CDKs) are serine/threonine kinases and their catalytic activities are modulated by interactions with cyclins and CDK inhibitors (CDKIs) [29]. The close cooperation among the three is necessary for ensuring orderly progression through the cell cycle. At the same time, they play an indispensable role in pro- cesses such as cell transcription, epigenetic, metabolism and stem cell self-renewal. Since each of CDK subunits only binds to its specific cyclins, the activation of the CDK cyclin complexes governing the transitions between cell cycle phases depends on the availability of the regulatory subunits. Thereby, cell machinery regulates cyclin oscillatory changes by controlling their synthesis and degradation at specific times, leading to the orchestrated progression of the cell cycle [30]. Cells lacking cyclin are blocked at the G1/S border [31]. The activation of cyclin $\mathrm{D}$ and cyclin $\mathrm{E}$ can promote the transition of cells from G1 phase to $S$ phase while the activation of cell division cycle gene $2(\mathrm{Cdc} 2)$ can promote the transformation of cells from $S$ phase to G2/M phase [29]. The activity of CDKs controls the cell cycle transcription and plays an important role in regulating spindle polymerization checkpoints.

The cell cycle checkpoint is significant for the cell to ensure the quality of DNA replication and chromosome allocation and is the regulatory path that controls the sequence and time of cell cycle transition. When DNA is damaged, checkpoints provide repair time by blocking the cell cycle, and respond to the damage by inducing transcription or genes that promote repair [32]. Some drugs can abolish cell cycle checkpoints at critical time points in cells, so that cells with damaged DNA have no time to be repaired and enter the next stage directly, thereby activating the apoptosis pathway and causing apoptosis. The DNA damage response (DDR) is responsible for detecting DNA damage, pausing the cell cycle and initiating DNA repair. According to the type of DNA damage, DNA damage checkpoints can be divided into ataxia telangiectasia and Rad3-related (ATR) protein or telangiectasia mutated (ATM) protein kinase phosphorylation and activate checkpoint kinase 1 (CHK1). ATR proteins are responsible for sensing stress and sending signals to the $\mathrm{S}$ and $\mathrm{G} 2 / \mathrm{M}$ checkpoints to promote injury repair. ATM can activate checkpoint kinase 2 (CHK2), which in turn activates the tumor suppressor gene tumor protein 53 (p53). Activated p53 can participate in many important signaling pathways that control cell proliferation and death, including cell cycle regulation, DNA repair, metabolism, senescence, autophagy, and apoptosis [33,34]. For example, p53 can directly regulate the expression levels of key kinases p 21 and CDK during cell cycle progression, leading to the inhibition of cyclin E CDK2 complex and G1 blockade [35]. The p21 protein inhibits cyclin at the G1 checkpoint and affects the cell's transition from the G1 phase to the S phase.

The cell cycle regulation is closely related to the reg- 
ulation of cell signaling pathways [36]. In tumor cells, signal pathways are involved in cell growth, proliferation, differentiation, protein synthesis, glucose metabolism and other activities. There are many pathways that regulate the cell cycle, such as ATR-CHK1/ATM-CHK2, JAKSTAT signaling pathway, p53 signaling pathway, NF- $к B$ signaling pathway, and $\mathrm{PI} 3 / \mathrm{AKT} / \mathrm{mTOR}$ signaling pathway $[35,37-39]$. Cell cycle regulators or drugs affect the expression of certain genes in these pathways or affect the expression of proteins and kinases to block or promote the normal progression of a certain cycle [40]. These processes can be utilized to artificially control the fate of tumor cells [41]. At the same time, some signaling pathways are ROS (reactive oxygen species)-responsive, and ROS, especially hydrogen peroxide, can act as the second messenger of cell signals [42]. ROS can upregulate the mRNA levels of cyclins that participate in the cell cycle to expedite G1 to $S$ phase transition [43]. Excessive elevation of ROS levels in tumors can lead to tumor cell cycle arrest, senescence or cell death (Fig. 2) [44].

\section{The action mechanism of the commonly used} chemotherapeutic drugs

There are many types of chemotherapeutic drugs and their mechanisms of action are not exactly the same.
According to the mechanism of action at the molecular level, chemotherapeutic drugs can be divided into several categories including alkylating agents, nucleotide reductase inhibitors and anti-metabolites, antibiotics and anti-tumor botanicals $[45,46]$. There are dozens or even hundreds of drugs in each category that act on different parts of tumor cells to inhibit or kill tumors. Common ones include destroying cell structure or preventing DNA replication, inhibiting enzyme or protein synthesis, destroying cellular structural components, and inhibiting tumor angiogenesis.

Some drugs such as alkylating agents, topoisomerase (Topo) inhibitors, and replication inhibitors, can destroy the structure of DNA or interfere with DNA replication. Alkylating agents (including nitrogen mustard, ethyleneimine, nitrosourea, methylxanthate, and epoxy compounds) can produce intra-chain or inter-chain cross links or transfer alkyl groups to guanine residues of DNA, leading to the formation of DNA base mispairs and preventing strand separation during DNA synthesis [47]. Although platinum drugs are also alkylating agents, they do not interact with biological macromolecules, but form a complex with the N7 position of guanine, thereby inhibiting DNA replication and transcription, and inducing apoptosis [48]. Topo inhibitors, which are divided into

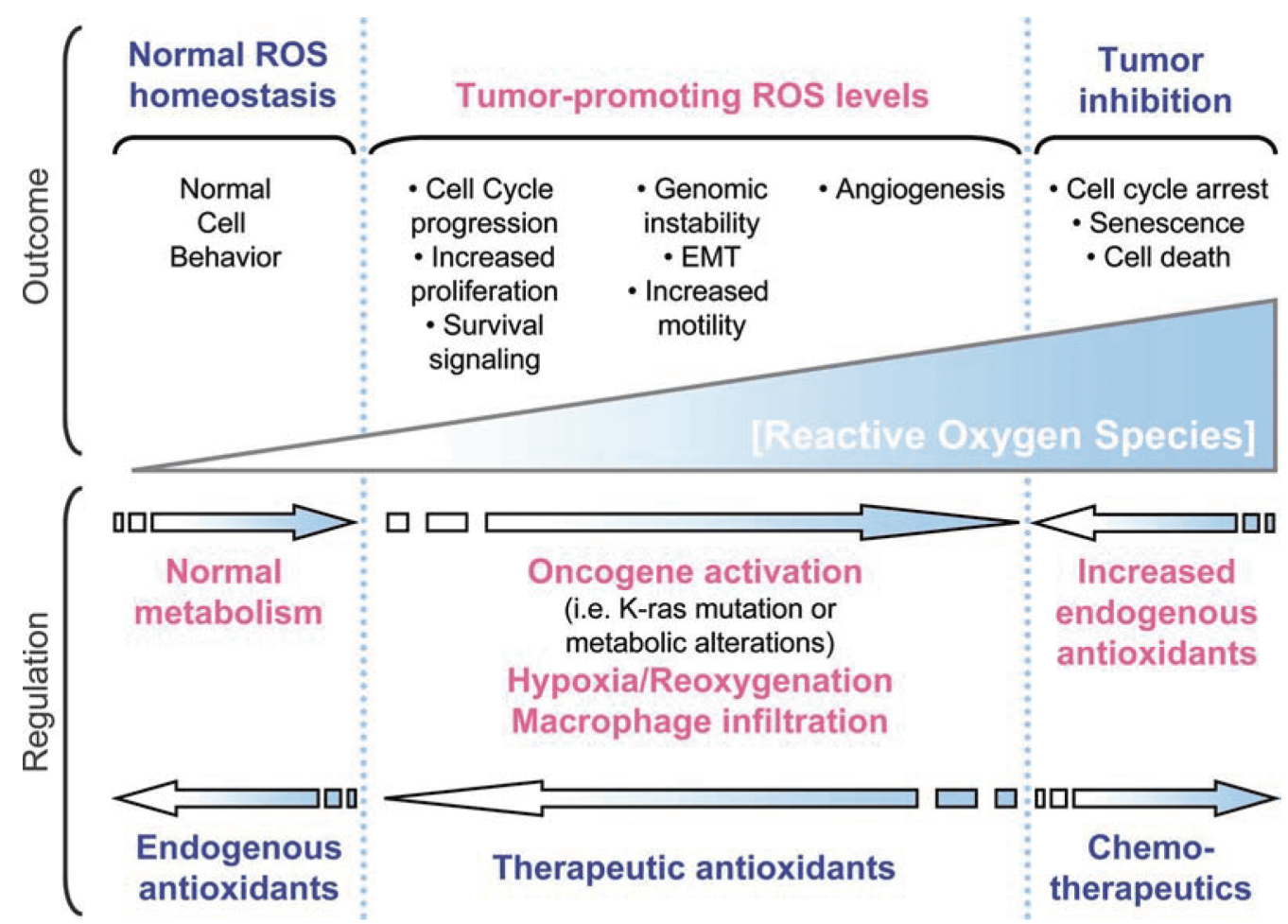

Figure 2 Generation, regulation and effects of cellular ROS. Reprinted with permission from Ref. [44]. Copyright 2010, Taylor \& Francis. 
topoisomerase I inhibitors (e.g., topotecan (TPT) [49], irinotecan [50], belotecan [51] and camptothecin (CPT) [52]) and topoisomerase II inhibitors (e.g., etoposide, teniposide), can inhibit the activity of Topo involved in DNA replication and transcription, causing DNA singlestrand or double-strand breaks. In addition, many common drugs, such as doxorubicin (DOX), mitoxantrone, coumarone, gemcitabine, mercaptopurine, CPT, PTX, vinorelbine, CDDP, carbachol and quinone drugs, can generate ROS and induce DNA damage to achieve anticancer effects $[53,54]$.

5-Fluorouracil (5-FU), deoxyfluorouridine, and pemetrexed (PMX) can inhibit thymine synthase and induce DNA damage [55-57]. Dihydrofolate reductase (DHFR) catalyzes the regeneration of tetrahydrofolate by reducing dihydrofolate. Tetrahydrofolate is a substance necessary for the synthesis of purine and thymine as well as glycine, methionine and serine. DHFR inhibition disrupts the biosynthesis of purine and thymine, affects DNA replication, and leads to cell death [58]. Methotrexate (MTX), raltitrexed, PMX, and pralatrexate can be used as DHFR inhibitors to affect DNA replication [59]. The diterpenoid nagilactone $\mathrm{E}$ (NLE) inhibits the proliferation of lung cancer cells by down-regulating cyclin B1-mediated G2 cell cycle arrest [60]. Actinomycin D can be inserted into the DNA double helix to form a covalent bond, destroy the DNA template function, hinder DNA replication, transcription and translation and other functions, and interfere with rRNA transcription and protein synthesis [61]. L-asparaginase is an important enzyme that can hydrolyze $L$-asparagine, a key raw material for tumor protein synthesis, to $L$-aspartate, which leads to the inhibition of tumor protein synthesis [62].

Some chemotherapeutic drugs can destroy cell structural components such as cell membranes, organelles, and biological macromolecules. Note that targeting the cell membrane also affects dormant cancer cells. Triphenylphosphonium (TPP) is a delocalized cationic lipid that can target mitochondria. Since the mitochondrial membrane is highly negatively charged, TPP can easily accumulate at and penetrate the mitochondrial membrane [63]. A lot of evidences prove that anthracyclines can quickly penetrate mitochondria and interact with multiple molecular targets including the multienzyme complex of electron transfer chain (ETC)/oxidative phosphorylation system (OXPHOS), mitochondrial DNA (mtDNA), and mitochondrial permeability transition pore (MPTP). Anthracycline-mediated mitochondrial damage leads to energy metabolism disorders and induces apoptosis [64]. Ribosomes are organelles responsible for protein synth- esis. Taking the ribosome as a target can not only interfere with the cancer cell's dependence on protein synthesis, reduce the high turnover rate of oncogenic protein levels (MYC, MCL1), but may also lead to apoptosis [65]. Studies have shown that oxaliplatin, DOX, mitoxantrone (DHAQ), and MTX can affect rRNA transcription levels [66]. CPT, flavonol, and roscovitine (ROSC) can act on the early rRNA processing while 5FU, MG-132, and homoharringtonine can act on late rRNA processing and inhibit ribosome synthesis. The blocking of rRNA transcription or early rRNA processing steps leads to disintegration of nucleoli, while the blocking of late rRNA processing steps keeps nucleoli intact. These drugs have good performance in targeting ribosomes and treating cancer [66]. The Golgi apparatus is involved in the processing and secretion of intracellular proteins. In tumor cells, all secreted proteins involved in tumorigenesis and development are modified, transported and secreted by the Golgi apparatus [66]. Celecoxib (CLX) is a specific inhibitor of COX-2, which can block the catalytic effect of COX-2 on promoting endothelial cell (EC) migration, enhancing vascular permeability, and up-regulating the expression of MMP-9 or VEGF [67]. CLX can inhibit the expression of Bcl-2 protein, interfere with the proliferation of tumor cells, thereby changing the permeability of mitochondria and promoting apoptosis [68]. Brefeldin A (BFA) is a signal transfer inhibitor that acts on the Golgi apparatus. After incubation, it collapses and merges into the endoplasmic reticulum, affecting vesicle transport and inhibiting the secretion of secreted proteins [69]. BFA can also increase the endoplasmic reticulum stress level of cancer cells, thereby inducing caspase-12 pathway-mediated apoptosis [70].

The characteristics of the infinite proliferation of tumors determine that the density of blood vessels around tumor cells is higher than that of normal cells [71]. Tumor cells secrete pro-angiogenic factors such as vascular endothelial growth factor (VEGF) to promote angiogenesis [72]. Therefore, to place tumor cells in a dormant or starvation state by inhibiting the secretion of angiogenic factors or blocking the flow of blood in the blood vessels is a promising treatment strategy for cancer [73]. PTX is a member of the taxane family and exerts an anti-tumor effect by targeting microtubules in cancer cells. Studies have shown that PTX has anti-angiogenic effects and induces tumor cell apoptosis [74]. Dihydroartemisinin (DHA), as an anti-angiogenic drug, inhibits the expression of fatty acid synthase (FASN) and inhibits EC tube production by inhibiting the STAT3 signaling pathway 
[75]. Bevacizumab is the first anti-angiogenic monoclonal antibody approved by the FDA [76]. Other anti-angiogenic drugs such as SUN, pazopanib, vandetanib, axitinib, regorafenib, cabozantinib, and lenvatinib have been approved by the FDA for the treatment of various cancer patients [77].

\section{Combination strategies of chemotherapeutic drugs and cell cycle regulation}

The proliferation of cancer cells is uncontrolled and not regulated by the negative feedback regulation. Compared with normal cells, cancer cells differ in the factors and proteins that regulate the cell cycle. From the action mechanisms of the typical chemotherapeutic drugs summarized above, it can be seen that although chemotherapy is highly toxic to cells, cancer cells may activate various DNA repair mechanisms or rely on checkpoints to repair DNA damage. The base damage caused by the alkylating agent and ROS will produce base mutations under the genotoxic stress during the cell replication of DNA, resulting in the failure of the drug. Or the cells may start to replicate the proteins needed to initiate DNA replication, such as the replication factor protein Cdt1, resulting in DNA to replicate again. DNA damage caused by a single chemotherapeutic drug may cause cells to acquire mutations or epigenetic modification, resulting in drug resistance. CCSA mainly works on cells during certain cell cycle. If the cells are artificially gathered at a certain phase, tumor cells can be killed more effectively by chemotherapeutic drugs. Therefore, using cell cycle inhibitors to block cells for a certain period during chemotherapy, the impact of drug resistance would be reduced, and the efficacy would be improved [78]. For example, Sun et al. [79] copolymerized carboxymethyl chitosan and diallyl disulfide to obtain nanogels, and further grafted valproic acid to give them the ability to reactivate CDDP and promote early apoptosis (Fig. 3). Subsequently, they used CDDP-resistant lung cancer cells (A549/DDP) as a model and showed that the system not only significantly increased intracellular ROS, but also improved the capacity of CDDP in G2/M arrest [79].

CCSA has limited effect on dormant cells. Generally, solid tumors are not sensitive to chemotherapeutic drugs because most tumor cells are at a low proliferation rate and the treatment is usually unsatisfactory. Even residual cancer cells can be the source of tumor recurrence and metastasis. Therefore, by regulating the cell cycle and driving dormant cells (G0 phase cells) back into the cell cycle, it may improve the sensitivity of tumors to chemo-

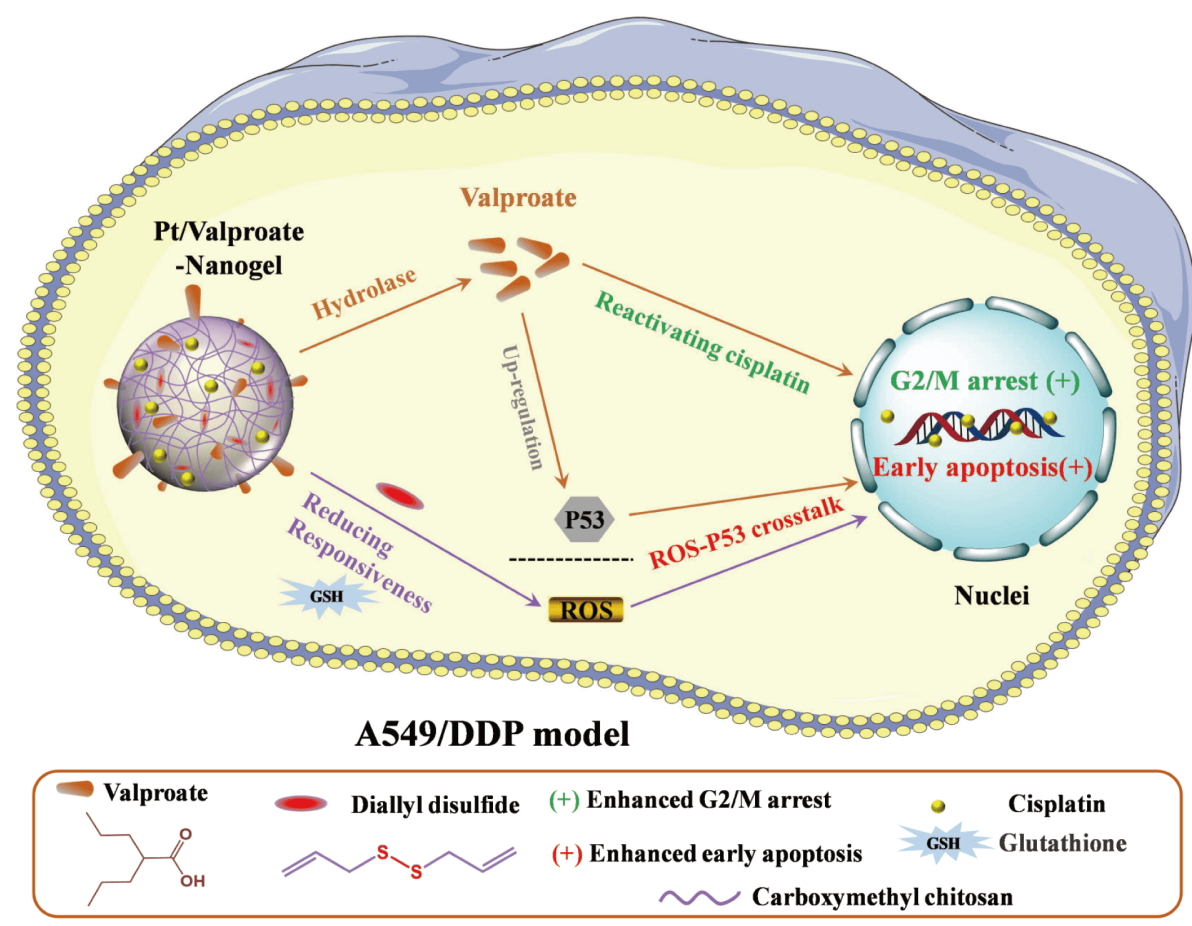

Figure 3 The mechanism of CDDP-coated nanogels to activate CDDP intracellularly and enhance early apoptosis. Reprinted with permission from Ref. [79]. Copyright 2020, Elsevier Ltd. 
therapeutic drugs. Based on this strategy, in addition to suppressing the cell cycle, tumors can also be treated by the combination of chemotherapy and cell cycle regulation that drive the cell cycle. The principle is usually to cancel the circulating checkpoints of tumor cells [80]. For example, as shown in Fig. 4, Cong et al. [81] used demethylcantharidin (DMC) to inhibit protein phosphatase 2A (PP2A), thereby accelerating cell division to improve the chemotherapy effect of CDDP.

To solve the problems of weak targeting, side effects, and drug resistance of chemotherapeutic drugs in the clinic, the strategies of combining cell cycle regulation with chemotherapy would be promising. Co-delivery systems make it possible to combine cell cycle regulatory agents and chemotherapeutic drugs [82-84].

\section{ADVANCES OF COMBINATION STRATEGIES FOR CANCER THERAPY}

Combination of chemotherapeutic agents affecting mechanisms regulating the same cell cycle phase should improve cytostatic and even cytotoxic efficacy of cancer treatments, but may not lead to higher specificity due to the similarity between normal and cancer cell proliferation. In the past few decades, various drug delivery sys-

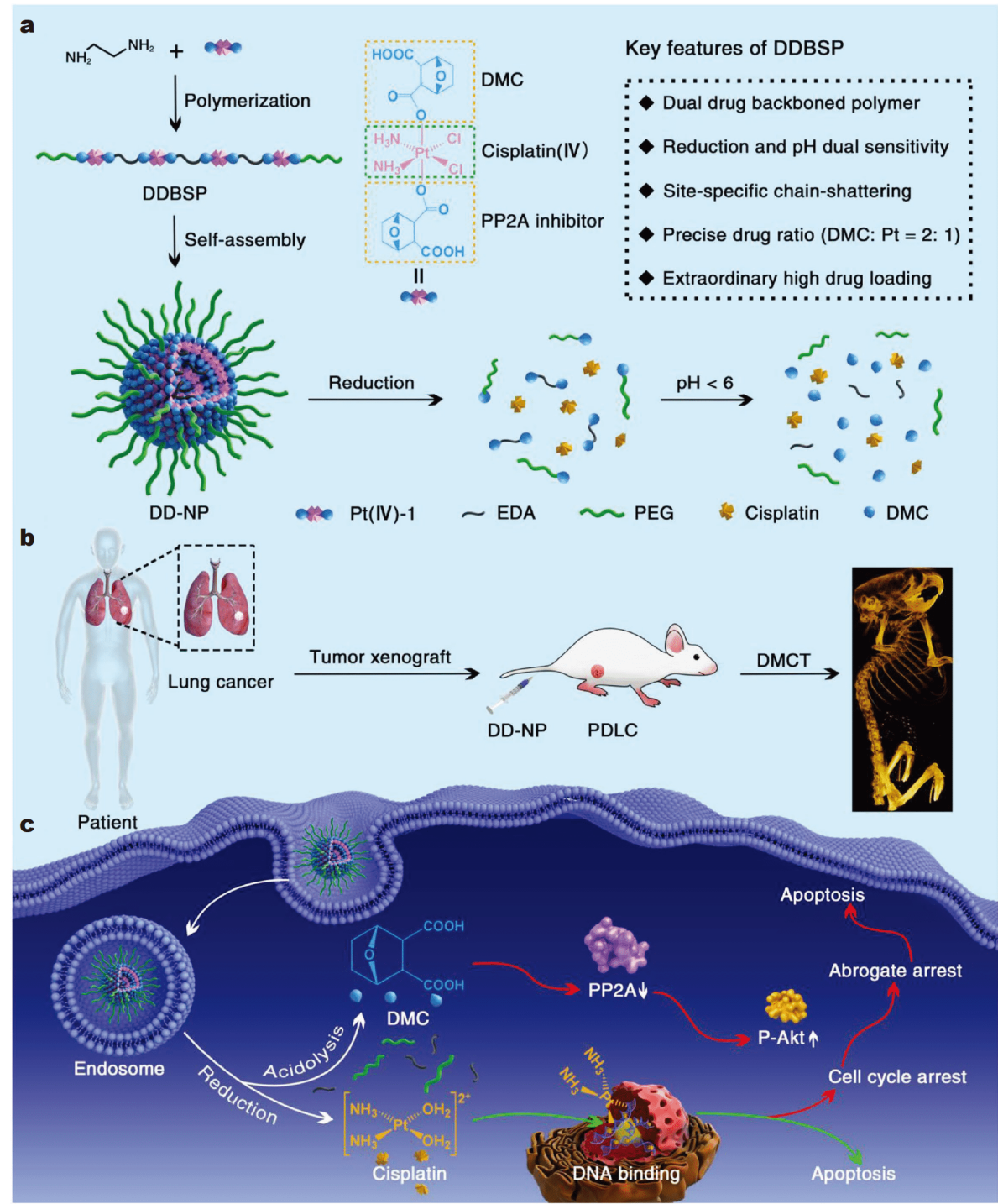

Figure 4 The construction and mechanism of dual drug backboned shattering polymeric theranostic nanomedicine (DDBSP). (a) The structure of $\mathrm{Pt}(\mathrm{IV})-1$, and the synthesis and decomposition of DDBSP. (b) Illustration of establishment of patient-derived lung cancer (PDLC) model and Pt-based drug-mediated computer tomography (DMCT) after intravenous injection with DD-NP. (c) The dual mechanism of DDNSP in cancer cells. Reprinted with permission from Ref. [81]. Copyright 2018, Wiley-VCH. 
tems have been proposed to extend the half-life of drugs, increase drug targeting, improve drug bioavailability, and reduce adverse reactions of chemotherapy drugs [16]. Many effective drug delivery vectors, such as liposomes [85], polymer NPs [86], micelles [87], exosomes [88], hydrogels [89], polymersomes [90], and drug-polymer conjugates [91], have been proposed to ensure that two or more drugs are delivered to the tumor site at the same time (Fig. 5) [92]. These nanocarriers are colloidal systems in the nanoscale size range and capable of loading small molecules as well as macromolecule drugs. Synergistic actions with decreased side effects are a main goal of co-delivery systems. The application of nanocarriers can prevent the degradation of drugs during long circulation, reduce side effects, increase drug payload, control drug release, improve drug solubility, and increase drug delivery by incorporating targeting ligands [93]. Co-delivery of cell cycle regulators and chemotherapeutics to the tumor site using drug carriers can play a synergistic effect and can greatly increase the tumor killing rate. At present, a large number of studies have used carriers to co-deliver cell cycle regulators and chemotherapeutic drugs [94-96]. Here, we mainly summarize the recent examples of co-delivery of cell cycle regulators and chemotherapy drugs from the perspective of drug carriers.

\section{Co-delivery of chemotherapeutic drugs and cell cycle inhibitors}

\section{Liposomes}

Liposomes encapsulate hydrophilic and hydrophobic drugs in their unique structure [97]. Drug-loaded lipo- somes have displayed the characteristics of enhanced accumulation in cancer tissues and prolonged circulation in blood [98]. In clinical applications, liposomal drugs with a particle size of less than $200 \mathrm{~nm}$ have been proven to be most useful for their ability to passively accumulate at sites of increased vasculature permeability and for their ability to reduce the side effects of the encapsulated drugs relative to free drugs [99]. Liposomes have been widely used to combine anticancer drugs of different therapeutic classes [100]. Studies have shown that functional vincristine plus dasatinib liposomes can induce the cell cycle arrest at the G2/M phase, inducing apoptosis, inhibit adhesion, migration, and invasion of breast cancer cells [101]. The immune cycle checkpoint inhibitors namely programmed cell death protein-1 (PD-1) and its ligand PD-L1 interact to protect tissues from the host immune defense system. The co-delivery of siRNA-PD-L1 (siPDL1) and imatinib (IMT) in liposomal NPs can synergistically knock down PD-L1, suppress the mTOR signaling pathway, restore the immunity of cytotoxic $\mathrm{T}$ lymphocytes (CTLs) and enhance anticancer efficacy in melanoma [102]. PLK-1 is a key player in the eukaryotic cell cycle and actively regulates the G2/M transition [103]. Studies have shown that the reduction of PLk-1 expression mediated by siRNA (siPLK1) leads to inhibition of G2/M phase of the cell cycle [104]. Using cationic liposomes to co-deliver the anticancer drug PTX and siPLK1 to the tumor cell can exert the synergistic effect of the two drugs and significantly improve the cytotoxicity of breast cancer [105]. The combination of all-trans retinoic acid stealth liposomes and the cytotoxic vinorelbine stealth liposomes was developed for preventing the relapse of breast cancer and for treating the cancer. The mechan-
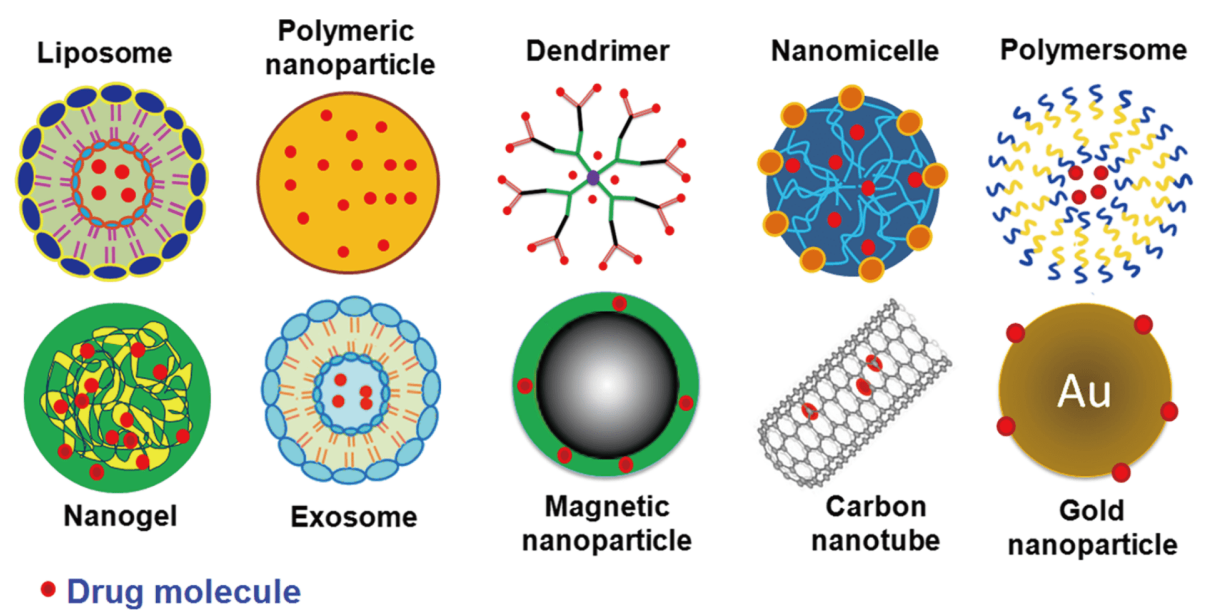

Figure 5 Several commonly used nanocarriers for cancer treatment. Reprinted with permission from Ref. [92]. Copyright 2016, Springer Science Business Media New York. 
isms of action were defined in two aspects: blocking breast cancer stem cells in the G0/G1 phase of mitosis, and inducing the differentiation of breast cancer stem cells [106]. The co-loading of resveratrol and DOX in liposomes has a good synergistic effect on the treatment of solid tumors. The evaluation of molecular pathways showed that the drug delivery systems for drug combinations can induce apoptosis by controlling the cell cycle and downstream inducing apoptosis proteins like caspase-3 and PARP [107]. Using folate receptor-targeted liposomes to carry celastrol and irinotecan for breast cancer therapy can significantly improve the targeted release of drugs to cancer cells (Fig. 6). This system can block the cell cycle in G2 and M phases, and significantly improve the sensitivity of cells to drugs and the therapeutic effect [108].

\section{Organic/inorganic NPs}

The organic NPs mentioned here are mainly polymer NPs, which are the most common drug carriers [109]. The advantages of polymer NPs are their high stability and mass production [110]. Owing to the modification of the polymer surface and the enhanced permeability and retention effect on tumors, polymeric NPs can actively or passively target and penetrate tissues, greatly improving the efficiency of drug delivery [111,112]. Co-delivering chemotherapeutics and chemosensitizers within polymeric NP carriers is a good choice. The stealth nanocarrier modified by methoxy polyethylene glycol (mPEG) synergistically delivers MTX and PMX to prepare NPs with controllable particle size and good sustained release in vitro (Fig. 7). The dual drug-loaded nano-delivery system can inhibit DNA replication and block lung cancer cells in $S$ phase, thereby inhibiting cell proliferation and promoting cell apoptosis [113]. Poly(lactic-co-glycolic acid) (PLGA)-based materials are frequently used in combination therapy of tumors [114]. Co-delivery of berberine and adriamycin via PLGA NPs using a conjugation/encapsulation strategy has been shown to exert a synergistic effect of the two drugs [115]. This method can significantly change the mitochondrial potential thus proving their mode of cell death via mitochondrial dependent pathway besides causing cell cycle arrest at G1 phase. Folate-polyethylene glycol-appended dendrimer

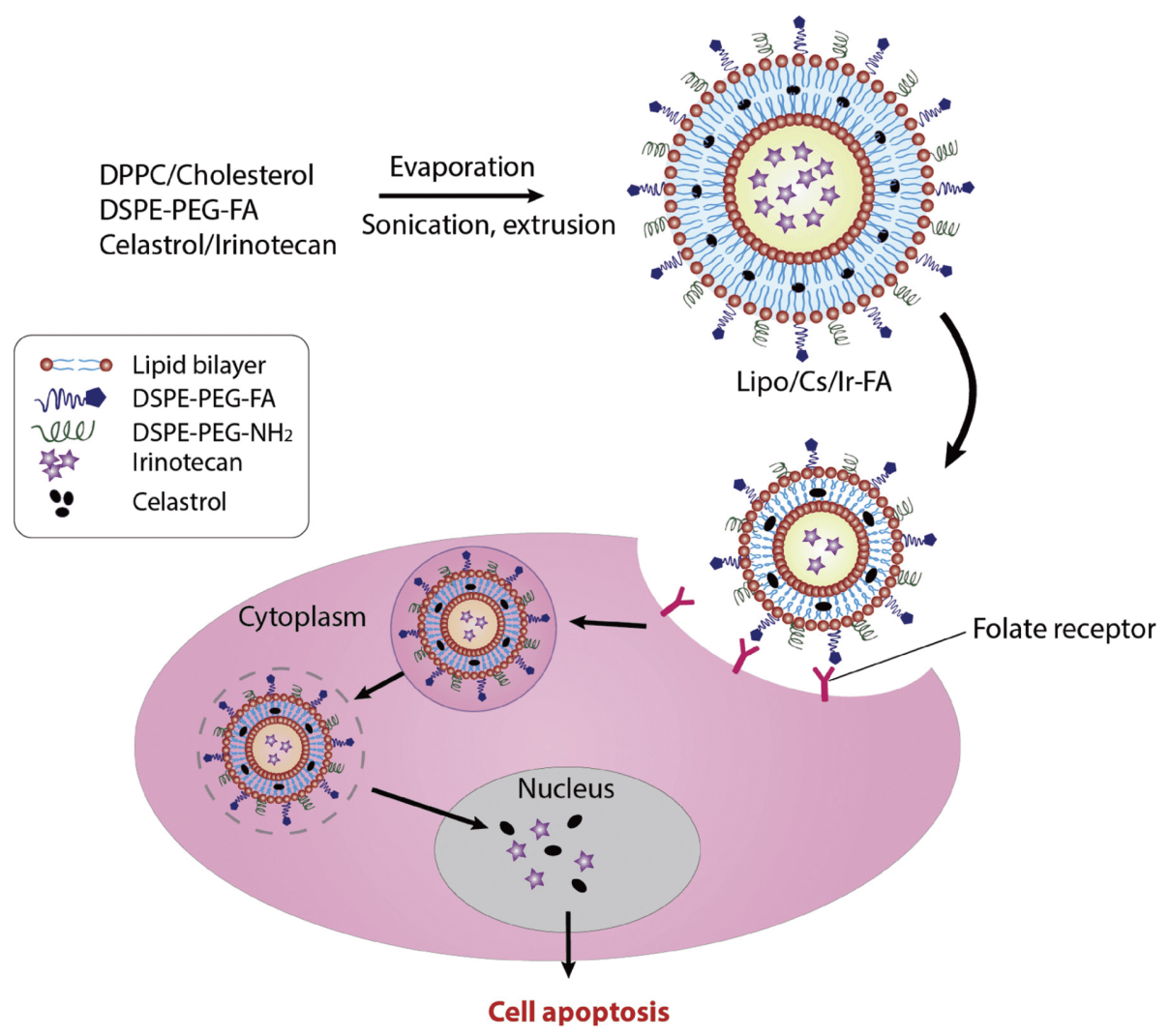

Figure 6 Schematic illustration of the preparation of folate receptor-targeted liposomes containing the combined drugs, celastrol and irinotecan, for breast cancer therapy. Reprinted with permission from Ref. [108]. Copyright 2018, Elsevier B.V. 


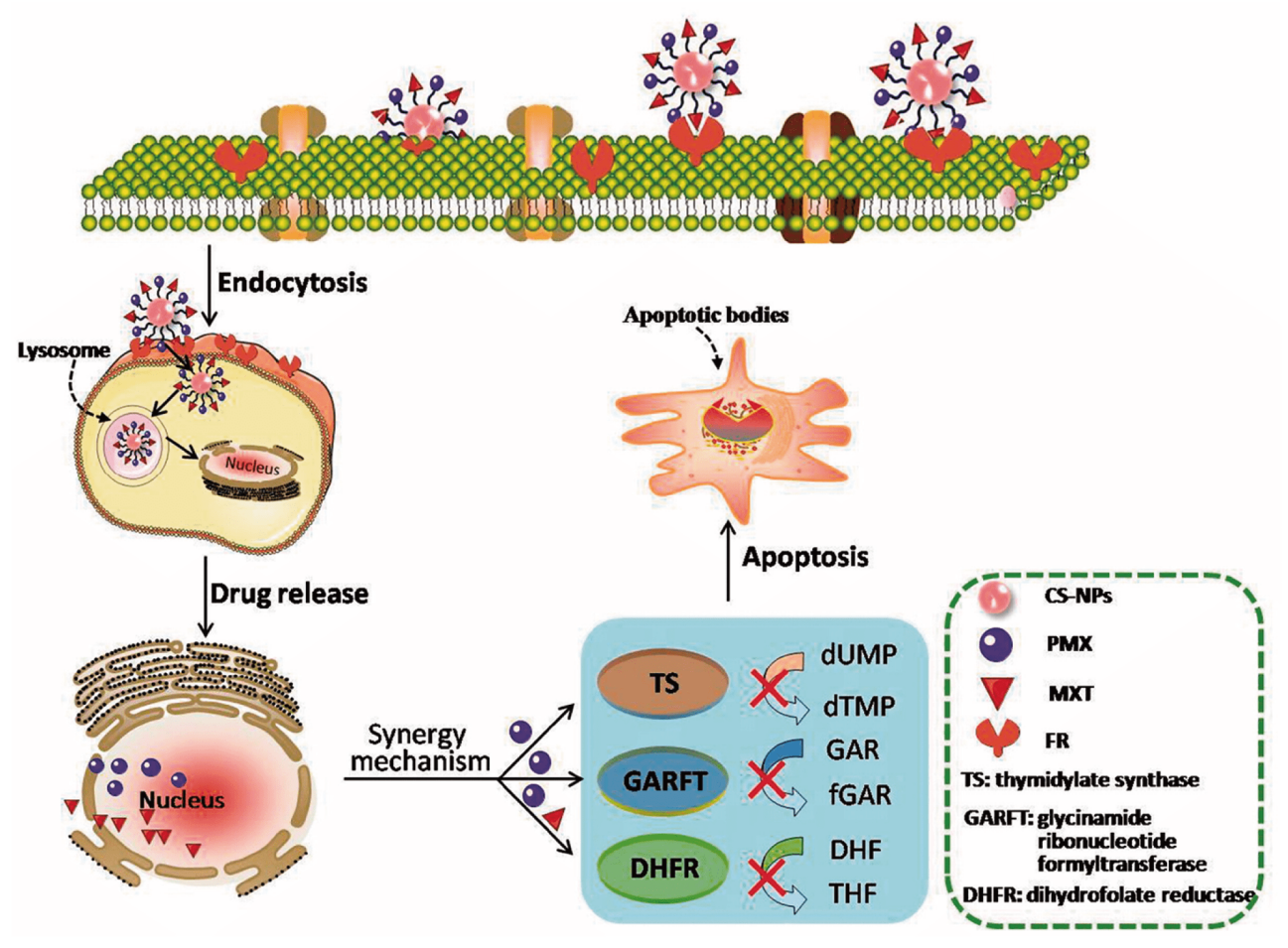

Figure 7 Schematic illustration for co-delivery processing of MTX/PMX-coloaded PCNPS in target tumor cells by active targeting. Reprinted with permission from Ref. [113]. Copyright 2018, Taylor \& Francis.

conjugate with glucuronylglucosyl- $\beta$-cyclodextrin (FolPEG-GUG- $\beta$-CDE) has the potential as a tumor-selective co-delivery carrier for siPLK1 and DOX. The ternary complex has a significant blocking effect on the cell cycle, and has shown potent anti-tumor activity in vivo without causing serious adverse effects [116].

Inorganic NPs are also commonly used drug co-delivery carriers. For example, a ratiometrically designed mesoporous silica nanoformulation utilizing remote loading to co-encapsulate CDK4/6 inhibitor palbociclib (PAL) and an autophagy inhibitor hydroxychloroquine (HCQ) has been demonstrated to have synergistic effects (Fig. 8a). This program significantly improves the delivery efficiency of the drug, blocks the cell G1 phase, and has a significant anti-tumor effect (Fig. 8b-d) [117]. Mesoporous silica nanocapsules (MSNCs) with a hollow mesoporous structure were proposed for co-loading of Ttype $\mathrm{Ca}^{2+}$ channel siRNA and DOX with high drug loading efficiency. It was demonstrated that co-loading of siRNA and DOX into the MSNCs had a synergistic therapeutic effect, which can reduce the intracellular $\mathrm{Ca}^{2+}$ concentration, block the G0/G1 phase, increase the intracellular drug concentration, and effectively overcome the MDR of breast cancer [118]. Similarly, photo- luminescent graphene quantum dots-encapsulated mesoporous NPs (GND@MSNs) with encapsulated DOX and cyclosporin (CsA) can induce DNA damage and block the cell cycle, opening up a new way to solve the complexity of lung cancer treatment [119]. Du et al. [120] developed a multifunctional mesoporous silica NP (MSNsGOx/PLL/HA) coated with poly(L-lysine) (PLL) and hyaluronic acid (HA) for co-delivery of glucose oxidase (GOx) and anticancer drug PTX. These NPs can effectively decompose glucose inside the tumor, produce toxic $\mathrm{H}_{2} \mathrm{O}_{2}$, inhibit the $\mathrm{G} 2 / \mathrm{M}$ phase, and further block energy supply. At the same time, the chemotherapeutic drug further exerts its pro-apoptotic effect to achieve synergistic treatment.

\section{Polymeric micelles}

The polymer micelle (PM) is composed of an inner hydrophobic core and an outer hydrophilic shell, so it can encapsulate hydrophobic drugs and isolate drugs from the external medium [121]. The use of a multifunctional drug co-delivery system with PMs as a carrier can increase the drug loading rate, reduce side effects, improve the efficacy of chemotherapy, and overcome MDR [119]. For example, redox-sensitive prodrug of epalrestat (EPR) 
a
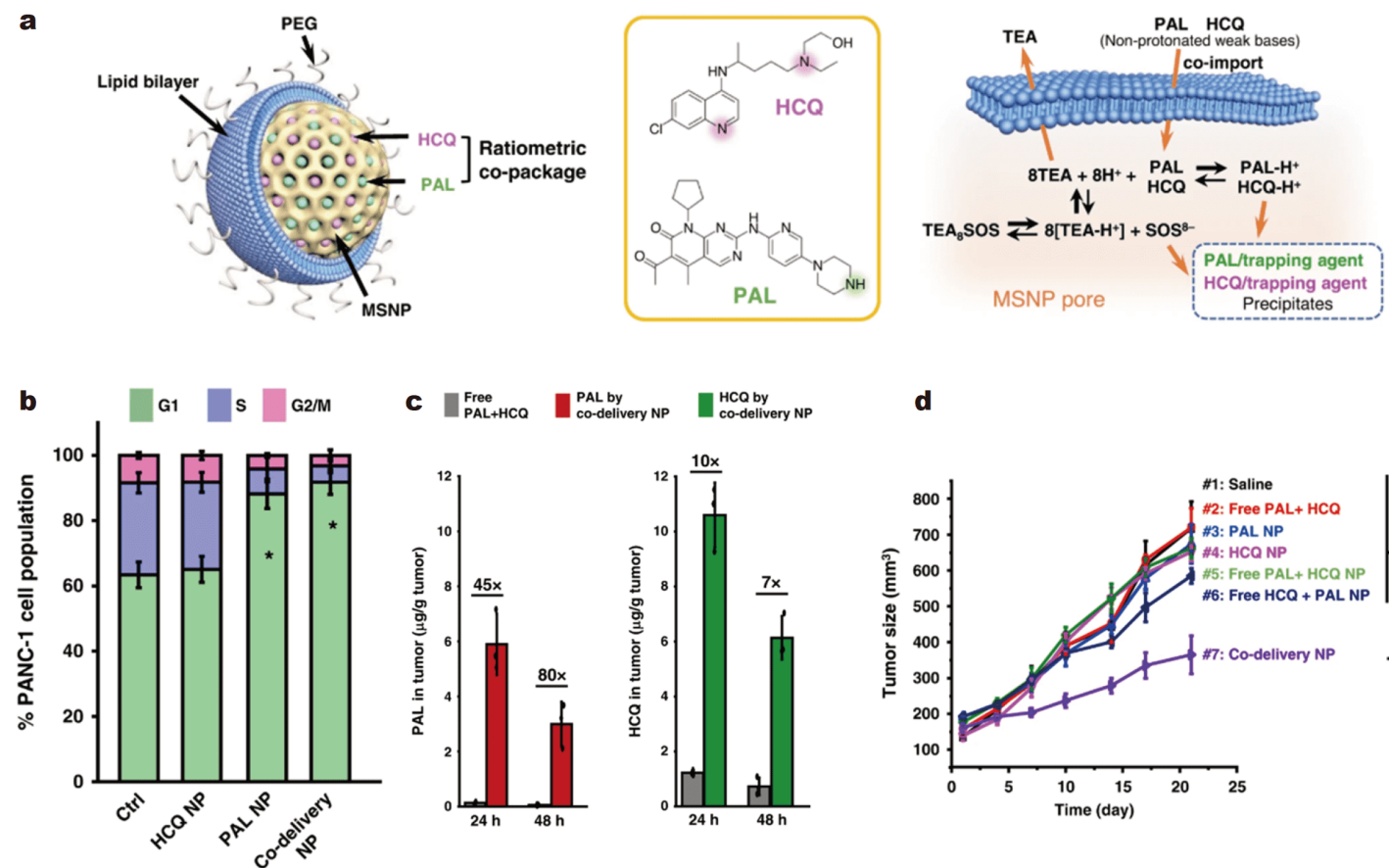

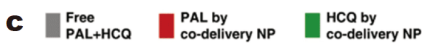

d
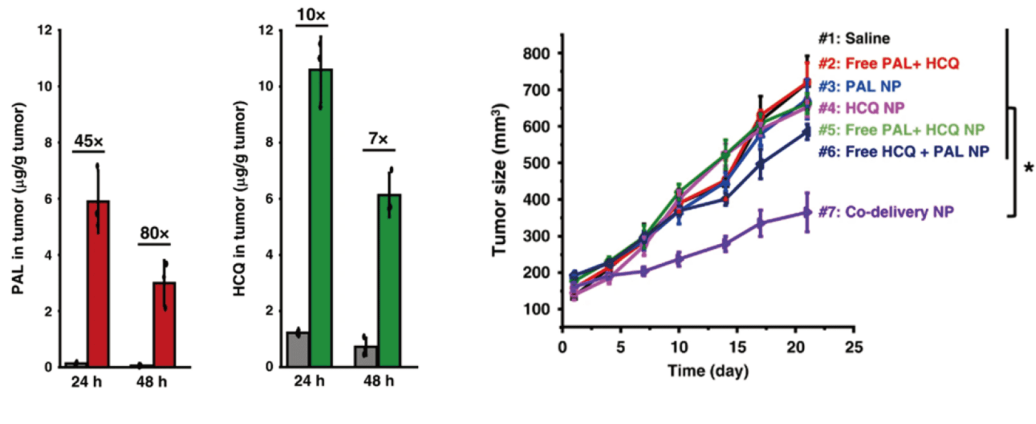

Figure 8 (a) Schemes depicting the structure of lipid-coated MSNP nanocarrier and the mechanism for simultaneous remote loading of PAL and HCQ using a trapping agent. (b) Cell cycle analysis using flow cytometry (triplicate). (c) PAL/HCQ content at the tumor site. (d) Efficacy study in subcutaneous PANC-1 xenograft model. Reprinted with permission from Ref. [117]. Copyright 2020, the Authors.

combined with tocopherol PEG succinate self-assembled into micellar prodrug (EPR-SS-TPPGS). This system was loaded with DOX at the same time to realize the codelivery of the two drugs and to achieve synergistic chemotherapeutic efficacy. Experimental results proved that EPR significantly enhanced the sensitivity of DOX, and induced apoptosis by inducing mitochondrial membrane depolarization and cell cycle arrest (Fig. 9) [122]. Chen et al. [123] designed Pluronic P105 DOX conjugate as a hydrophobic core to entrap another anticancer drug PTX with Pluronic F127 to form the dual drug-loaded mixed micelles (PF-DP). Co-delivery of hydrophilic DOX and hydrophobic PTX can achieve the synergistic effect of the two drugs, which is more effective in blocking the cell cycle and inducing cell apoptosis than single drug. 6Mercaptopurine (MP) is a purine antimetabolic prodrug. By coupling hydrophobic MP and thio-HA, a dual-sensitive polymeric drug conjugate (HA-SS-MP) was synthesized, which can be used as a carrier for DOX. The results showed that DOX-loaded HA-SS-MP blocked the parental HCT116 colon cancer cells in S phase, while cell block was observed in G0/G1 phase in HCT116-CSCs [124]. Han et al. [125] prepared DOX and rhubarb (RHE) co-loaded PMs (nano-DOX/RHE) to achieve the co- transmission of DOX and RHE and reduce the drug resistance of ovarian cancer cells. Nano-DOX/RHE inhibited the proliferation of ovarian cancer cells and induced apoptosis by inducing cell cycle arrest. mPEG- $b$ oligo( $\varepsilon$-caprolactone) micelles with co-encapsulated quercetin (QCT) and superparamagnetic iron oxide NPs (SPIONs) were developed for the treatment of liver cancer. Among them, SPION-loaded polymeric micelles can increase the sensitivity of magnetic resonance imaging (MRI) and improve the biocompatibility. QCT-SPIONloaded micelles can block the cell cycle in G0/G1 phase, which is effective in tumor detection and treatment [126].

\section{Hydrogels}

Hydrogels are hydrophilic polymer networks that can absorb huge volumes of water and can undergo swelling and shrinkage. This feature promotes hydrogels to control drug release, making them a widely used drug carrier in recent years [127]. Hydrogels can be stimulated by external environment such as heat, $\mathrm{pH}$, light and ultrasound, which enables in-situ gelation and controlled drug release, greatly improving the convenience and efficiency of drug delivery [128]. Both natural and synthetic hydrophilic polymers can form hydrogels through physical 


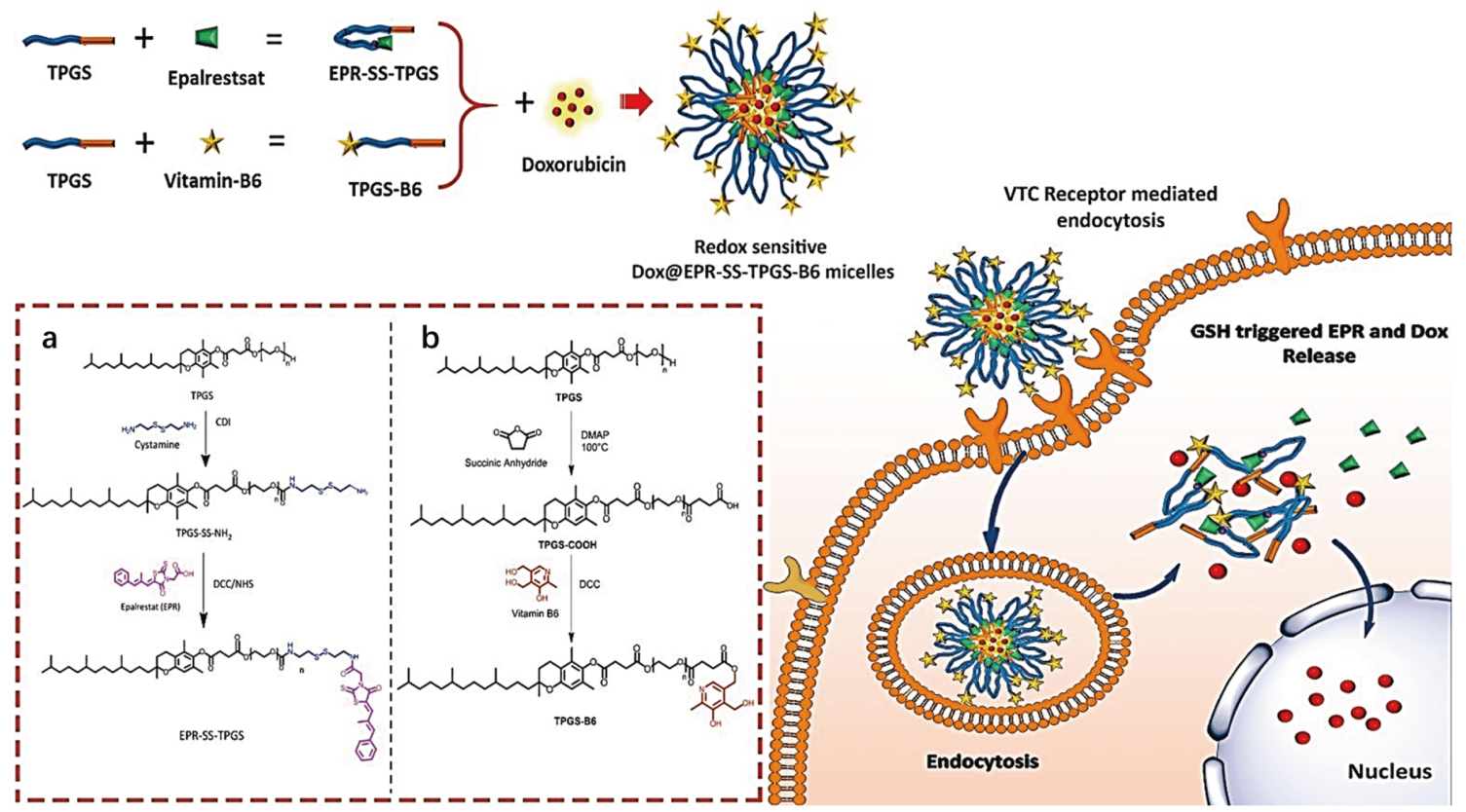

Figure 9 Schematic illustration of vitamin B6 transporting membrane carrier (VTC) receptor-mediated intracellular uptake of DOX-loaded EPRSSTPGS-B6 micelles and redox-responsive drug release. Inset shows the synthetic scheme of (a) EPR-SSTPGS and (b) TPGS-B6 conjugates. Reprinted with permission from Ref. [122]. Copyright 2019, Royal Society of Chemistry.

or chemical crosslinking. There have been many studies on hydrogels for co-delivery of chemotherapeutics and cell cycle regulators. Lv et al. [129] established a chemoimmunotherapy system of DOX, interleukin-2 (IL-2) and interferon- $\gamma($ IFN- $\gamma)$ based on poly $(\gamma$-ethyl- $L$-glutamate)PEG-poly $(\gamma$-ethyl-L-glutamate) (PELG-PEG-PELG) hydrogel for local treatment of melanoma xenograft. DOX/ IL-2/IFN- $\gamma$ co-loaded hydrogel can enhance the anti-tumor effect by increasing the apoptosis rate and G2/S cycle block. The self-assembling peptide hydrogel synergistically delivers DOX and CUR, and has a good curative effect on head and neck cancer cells, and it can control the release rate of the drug based on its aqueous solubility. Studies have confirmed that the drug-loaded hydrogel can enhance the apoptosis response, interfere with the cell cycle process, and significantly change the expression profile of apoptosis/anti-apoptosis genes [130]. Wu et al. [131] prepared an in-situ thermosensitive hydrogel based on PEG and PEG- $b$-PELG for the co-delivery of interleukin-15 (IL-15) and CDDP to jointly improve the anti-tumor effect on melanoma (Fig. 10a). IL15 and CDDP co-loaded hydrogels can show a synergistic therapeutic effect by regulating the immune function and inducing cell cycle arrest. In addition, they used the Schiff base reaction to prepare in situ hydrogels to co-deliver $\mathrm{ME}$ and 5-FU [132]. In vitro degradation and drug release studies demonstrated that this hydrogel could release $\mathrm{ME}$ and 5-FU in response to $\mathrm{pH}$, and had a synergistic inhibitory effect on colon cancer cell cycle progression and cell proliferation (Fig. 10b). Ma et al. [133] developed a biodegradable thermosensitive hydrogel PELG-PEG-PELG to co-deliver PLK1shRNA and DOX for the synergistic treatment of osteosarcoma. This system showed a significant synergistic effect on tumor cell toxicity, PLK1 silencing efficiency, cell apoptosis and cell cycle arrest in vitro.

\section{Other drug delivery systems}

Other drug carriers such as exosomes and polymersomes also have applications in the co-delivery of chemotherapeutic drugs and cell cycle regulators. Exosomes are small $(<150 \mathrm{~nm})$ extracellular vesicles that contain genetic material, proteins, and lipids [88]. Exosomes have natural material transportation properties, intrinsic long-term circulatory capability, and excellent biocompatibility, making them have great potential to be drug delivery vehicles [134]. Appropriate modification of exosomes can improve the stability and efficacy of imaging probes and therapeutics while enhancing cellular uptake, which are promising for use as vectors for clinical application [135]. Liang et al. [136] used engineered exosomes to simultaneously deliver the anticancer drug 5-FU and miR-21 
inhibitor oligonucleotide (miR-21i) to Her2-expressing cancer cells (Fig. 11). The results showed that the 5-FU and miR-21i co-delivery system based on the engineered exosome can effectively facilitate cellular uptake and significantly down-regulate the expression of miR-21 in 5-FU resistant cells, ultimately leading to cell cycle arrest, tumor proliferation decrease, and increase apoptosis.

A measure of carrier performance is to improve the bioavailability of anticancer drugs and reduce the toxicity to the body. Polymersomes just meet this requirement. Polymersome-based therapeutic drug delivery strategies have shown remarkable potential in the therapy of cancer due to their physical and chemical robustness, high drug loading capability, high colloidal stability, significant biocompatibility, and their ability to encapsulate both hydrophilic and hydrophobic molecules [137]. Qin et al.
[138] constructed a folate-decorated PCL-ss-PEG-ssPCL-based redox-responsive polymersome (FA-TQR-CoPS) and simultaneously loaded with the P-gp inhibitor tariquidar (TQR) and the anticancer drug DOX as well as PTX. After folate-mediated endocytosis, the chemosensitizer TQR was slowly released to interdict the P-gp efflux activity. At the same time, PTX and DOX were released into the cytoplasm to respond to GSH and play a synergistic effect (Fig. 12). In addition, TQR significantly enhanced the cytotoxic and pro-apoptotic activities of DOX and PTX on MCF-7/ADR, and the cell cycle was deeply blocked in G2/M phase. This nano-system provides a powerful platform for multi-drug delivery and overcoming drug resistance. Table 1 briefly summarizes examples of various nanocarriers co-delivering chemotherapeutic drugs and cell cycle inhibitors.
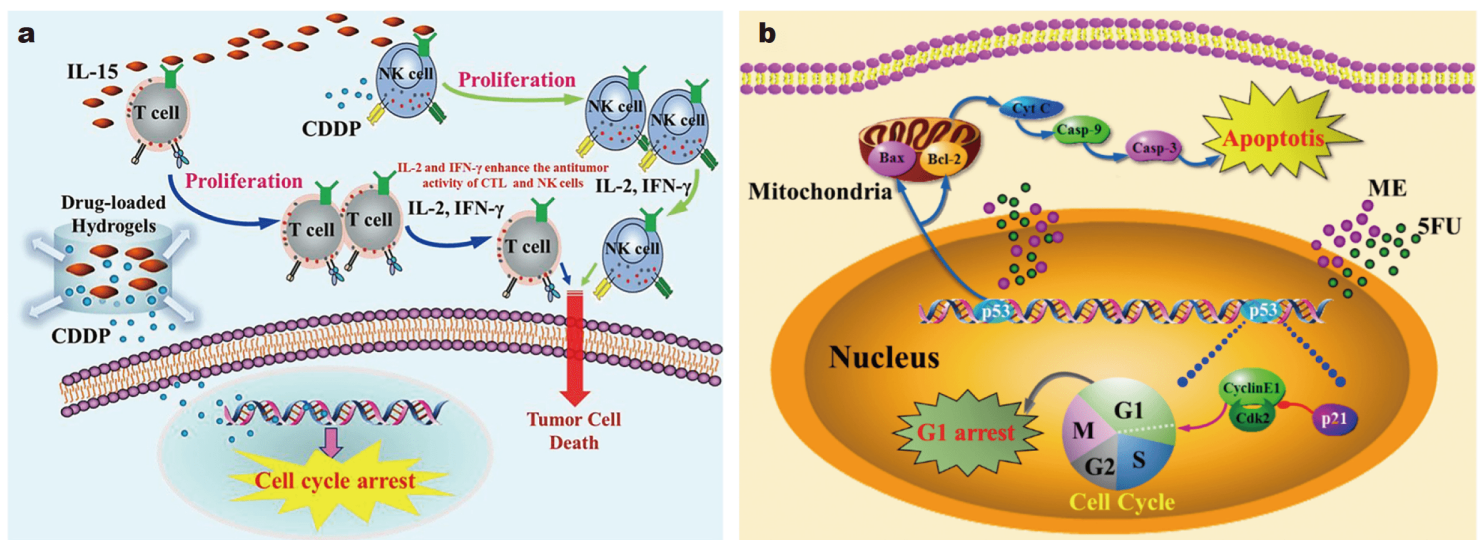

Figure 10 (a) Schematic representation of the mechanism for synergistic antitumor effects of localized co-administration of IL-15 and CDDP released from the mPEG- $b$-PELG hydrogels. Reprinted with permission from Ref. [131]. Copyright 2017, Elsevier B.V. (b) The schematic illustration of synergistic antitumor effects of combination treatment of ME and 5FU released from the PFA/PPLL hydrogels. Reprinted with permission from Ref. [132]. Copyright 2015, Elsevier Ltd.

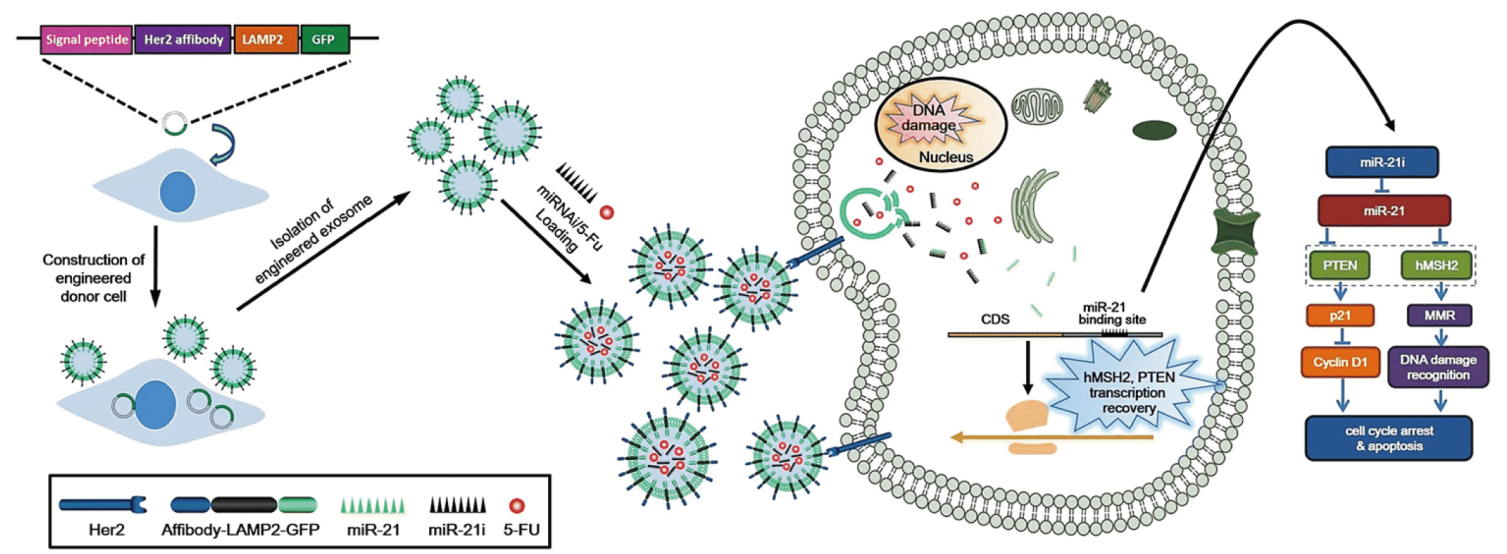

Figure 11 Engineered exosome-based nanocarrier for simultaneous delivery of 5-FU and miR-21i to HCT-1165FR human colon cancer cells for enhancing chemotherapy efficacy. Reprinted with permission from Ref. [136]. Copyright 2020, The Author(s). 


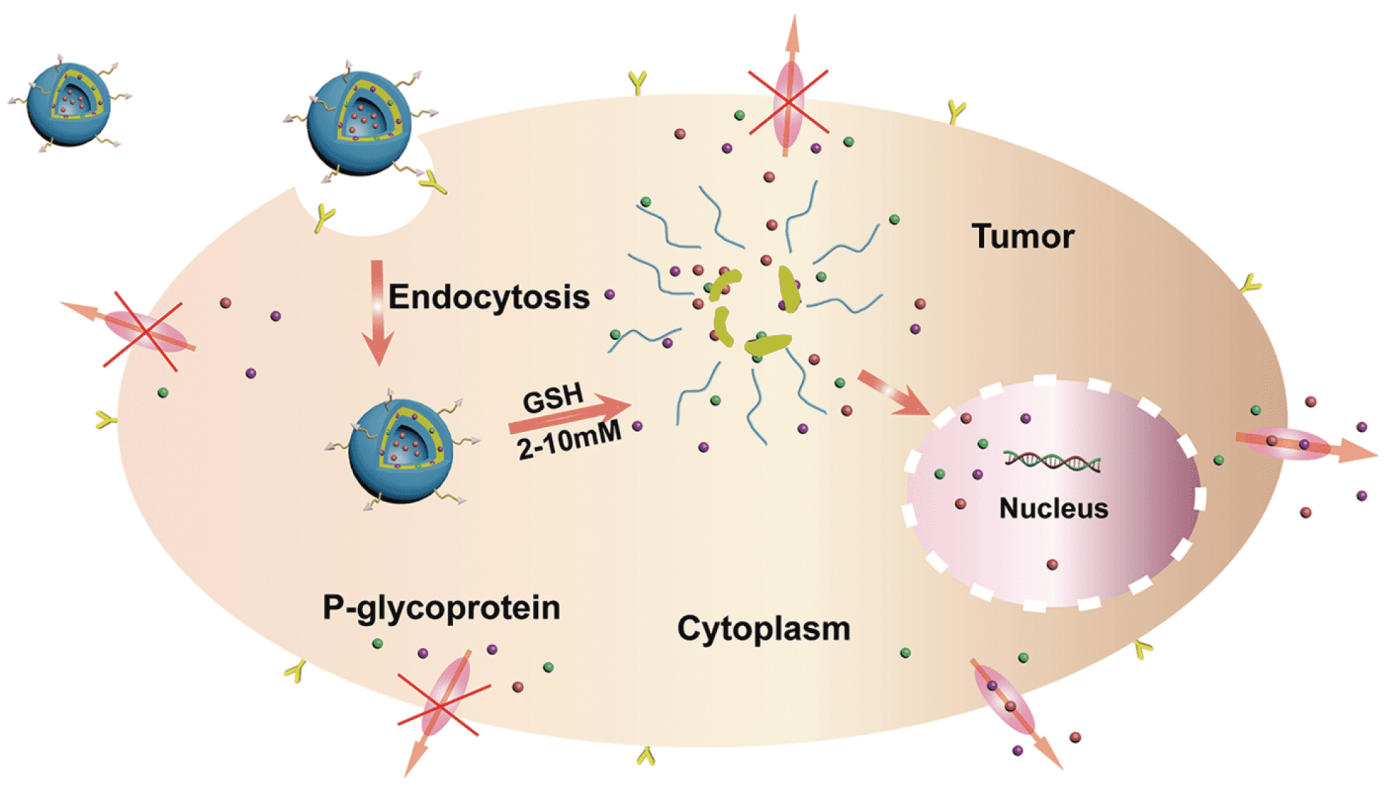

Figure 12 Illustration of folate-targeted redox-responsive polymersome for co-delivery of chemotherapeutic drugs and tariquidar (FA-TQR-Co-PS) to achieve tumor targeting and redox-responsive drug release, exerting MDR reversal effects. Reprinted with permission from Ref. [138]. Copyright 2018, American Scientific Publishers.

Table 1 The summary of co-delivery systems of chemotherapeutic drugs and cell cycle inhibitors

\begin{tabular}{|c|c|c|c|c|c|}
\hline Nanocarrier type & Chemotherapeutic drug & Cell cycle inhibitors & Targeted cell cycle & Therapeutic use & Ref. \\
\hline \multirow{5}{*}{ Liposomes } & Dasatinib & Vincristine & $\mathrm{G} 2 / \mathrm{M}$ & $\begin{array}{l}\text { Lung metastasis of } \\
\text { breast cancer }\end{array}$ & {$[101$} \\
\hline & Paclitaxel & siPLK1 & $\mathrm{G} 2 / \mathrm{M}$ & Breast cancer & {$[105$} \\
\hline & Vinorelbine & All-trans retinoic acid & G0/G1 & Breast cancer & {$[106$} \\
\hline & Doxorubicin & Resveratrol & $\mathrm{G} 2 / \mathrm{M}$ & Head and neck cancer & {$[107$} \\
\hline & Irinotecan & Celastrol & $\mathrm{G} 2 / \mathrm{M}$ & Breast cancer & {$[108$} \\
\hline \multirow{3}{*}{ Polymeric nanoparticles } & Methotrexate & Pemetrexed & $S$ & Lung cancer & {$[113$} \\
\hline & Doxorubicin & Berberine & $\mathrm{G} 1, \mathrm{G} 2 / \mathrm{M}$ & Breast cancer & {$[115$} \\
\hline & Doxorubicin & $\begin{array}{l}\text { Folate-polyethylene, glu- } \\
\text { curonylglucosyl- } \beta \text {-cyclo- } \\
\text { dextrin }\end{array}$ & $\mathrm{G} 2 / \mathrm{M}$ & $\begin{array}{l}\text { Oral squamous cell } \\
\text { carcinoma }\end{array}$ & {$[116$} \\
\hline \multirow{3}{*}{$\begin{array}{l}\text { Mesoporous silica } \\
\text { nanoparticles }\end{array}$} & Hydroxychloroquine & Palbociclib & G1 & Pancreatic cancer & {$[117$} \\
\hline & Doxorubicin & $\begin{array}{c}\text { T-type } \mathrm{Ca}^{2+} \text { channel } \\
\text { siRNA }\end{array}$ & G0/G1 & Breast cancer & {$[118$} \\
\hline & Paclitaxel & Glucose oxidase & $\mathrm{G} 2 / \mathrm{M}$ & Liver cancer & {$[120$} \\
\hline \multirow{4}{*}{ Polymeric micelles } & Doxorubicin & Epalrestat & $\mathrm{G} 2 / \mathrm{M}$ & Breast cancer & {$[122]$} \\
\hline & Doxorubicin & 6-Mercaptopurine & $\mathrm{S}, \mathrm{G} 0 / \mathrm{G} 1$ & Colon cancer & {$[124$} \\
\hline & Doxorubicin & Rhubarb & G0/G1 & Ovarian cancer & {$[125$} \\
\hline & $\begin{array}{c}\text { Superparamagnetic iron } \\
\text { oxide nanoparticles }\end{array}$ & Quercetin & G0/G1 & Liver cancer & {$[126$} \\
\hline \multirow{4}{*}{ Hydrogels } & Doxorubicin & $\begin{array}{l}\text { Interferon- } \gamma \text {, } \\
\text { interleukin-2 }\end{array}$ & G1/S & Melanoma xenograft & {$[129$} \\
\hline & Cisplatin & Interleukin-15 & G1/S & Melanoma & {$[131$} \\
\hline & 5-Fluorouracil & Metformin & G1 & Colon carcinoma & {$[132$} \\
\hline & Doxorubicin & Plk1shRNA & $\mathrm{G} 2 / \mathrm{M}$ & Osteosarcoma & {$[133$} \\
\hline
\end{tabular}




\section{Combination of chemotherapeutic drugs and agents promoting cell cycle}

Promoting cell cycle progression is not in the literal sense, but is forcing the cycle progression of cancer cells that are in a low metabolic state or whose DNA is damaged. For example, the reduction of hormone chemotherapy will induce the G0/G1 blockade of the tumor, thereby producing chemotherapy resistance [139]. In this situation, promoting cell cycle progression can increase the sensitivity of cancer cells to chemotherapeutic drugs. For example, gonadal hormone, growth hormone, thyroid hormone, and insulin can increase the proportion of tumor cells in $S$ phase and play a role in chemosensitizing of the tumor (Fig. 13) [140,141]. In the in vivo experiment using a mouse model, the survival time of mice injected with growth hormone and carboplatin was significantly longer than that of mice injected with growth hormone and carboplatin alone as well as somatostatin plus carboplatin [142]. Insulin can markedly increase the cell population of the $S$ phase, while it can decrease the cell number of the G0/G1 phase in Eca 109 and Ls-174-t cells [143]. Compared with 5-FU, insulin/5-FU treatment can enhance tumor cell apoptosis and change the level of TS and TS ternary complex. Triiodothyronine (T3) can enhance the chemical sensitivity of MCF-7 to 5-Fu and TAX, as well as advance cells from G0-G1 phase to $S$ phase, which may provide a new adjuvant therapy for future treatment of breast cancer, especially for breast cancer with hypothyroidism during chemotherapy [141].

On the other hand, when intracellular DNA is damaged, ATM and ATR are activated, starting checkpoint control and stopping cell cycle progression to coordinate repair of DNA damage [144]. When the activity of CHK1 or CHK2 is inhibited, the cell cycle checkpoint is abolished, expediting the cell cycle progression of unrepaired DNA damage, promoting the activation of the apoptosis pathway, and making the cell prone to apoptosis. The use of checkpoint kinase inhibitors in combination with DNA-damaging chemotherapeutic drugs can enhance tumor killing rates and eliminate cell cycle-mediated resistance to chemotherapeutic drugs. UCN-01, adavosertib, SRA737, XL-844, and GDC-0575 are all checkpoint kinase inhibitors, which have been studied in combination with chemotherapy drugs [145-149]. The development of specific carriers to co-deliver cell cycle checkpoint inhibitors and chemotherapeutic drugs can greatly improve the efficiency of drug delivery and reduce the toxic side effects of drugs on the body. For example, DMC, as a PP2A inhibitor, enhances the antitumor activity with DNA damaging agents by specifically inhibiting PP2A, without evident acute or chronic toxicity [81]. Studies have shown that DMC and platinum drugs have a

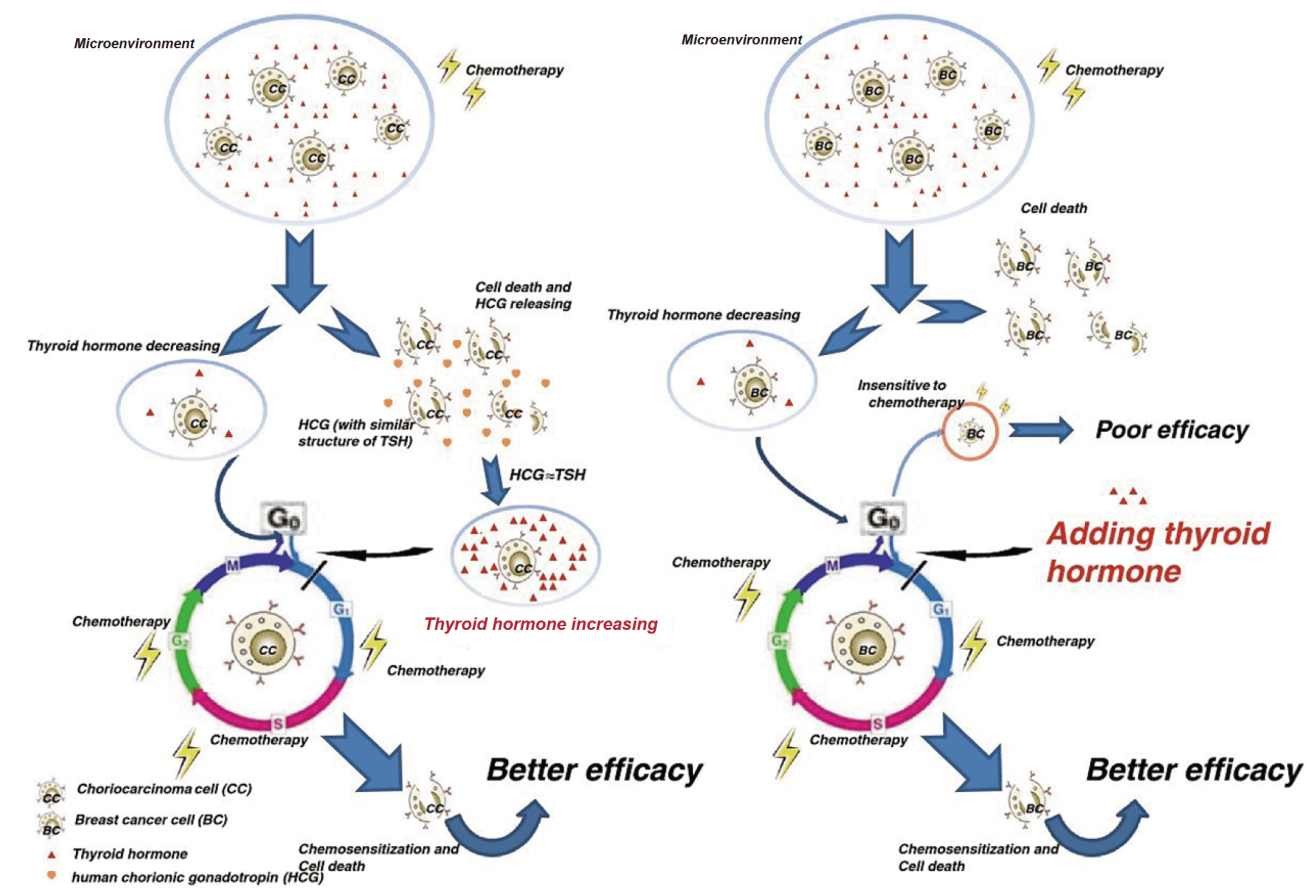

Figure 13 Possible mechanism of choriocarcinoma chemotherapy and chemosensitization role of thyroid hormone in breast cancer. Reprinted with permission from Ref. [141]. Copyright 2013, Huang et al.; licensee BioMed Central Ltd. 
good synergistic effect [150]. It can accelerate cells from G1 to $S$ phase, block cells in G2/M phase, and lead to apoptosis [151]. There are many experimental protocols for co-delivery of DMC and platinum drugs. Cong et al. [81] synthesized DMC and CDDP in a 2:1 ratio, and used ethylenediamine to connect the two prodrugs to achieve precise delivery of the two drugs. Wang et al. [152] combined DMC with oxaliplatin and coupled it with the amphiphilic biodegradable copolymer mPEG- $b$-P(LAcoMCC/OH) to form a conjugated polymer to achieve the coordinated release of the two drugs (Fig. 14). Similarly, Zhou et al. [153] connected DMC and CDDP in series and then coupled with mPEG- $b-\mathrm{P}(\mathrm{LA}-\mathrm{coMCC} / \mathrm{OH})$ by a $\mathrm{N}, \mathrm{N}$-dicyclohexylcarbodiimide (DCC)/N-hydroxybenzotrizole (HOBt) method to form a polymer-(tandem drugs) conjugate (polymer-Z-DMC-CIS). In addition, the study by Fan et al. [154] demonstrated that shRNA-induced CHK1 silencing can override G2/M arrest and impair homologous recombination (HR) repair by reducing breast cancer susceptibility gene 1 (BRCA1) ex- pression. Studies have shown that CCT245737, an orally bioavailable CHK1 inhibitor, can significantly enhance the sensitivity of cells to etoposide. This combined method has a strong synergistic anti-cancer effect in the treatment of chronic myeloid leukemia (CML). Sanij et al. [155] found that the RNA polymerase I transcription inhibitor CX-5461 and PARP inhibitors (PARPi) can synergistically exacerbate replication stress, aggravate DNA damage and enhance synthetic lethal interactions of PARPi with HR deficiency in the treatment of high-grade serous ovarian cancer (HGSOC).

\section{CONCLUSIONS AND PERSPECTIVES}

The combination of chemotherapeutic drugs is the main method of clinical response to chemoresistance in recent years, but there are still many problems such as side effects and poor efficacy. The emergence of drug delivery systems appropriately solves these problems. The co-delivery carrier is a bridge to achieve effective coordination of multiple drugs. Synergistic effects and reduced side

a

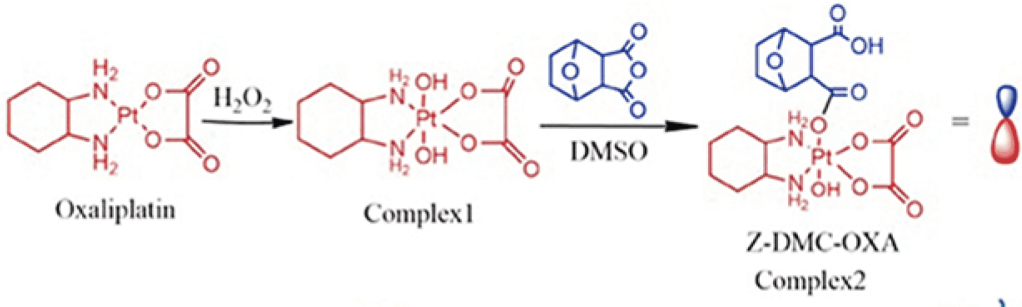

b
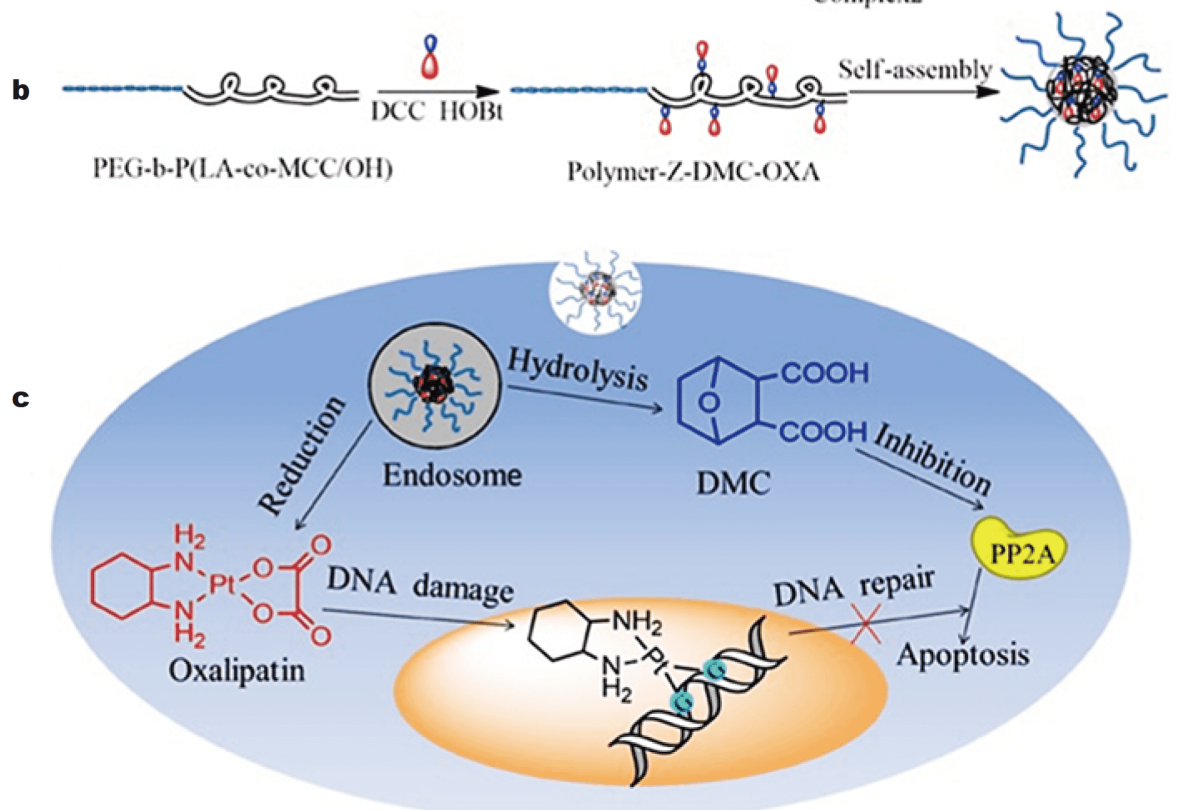

Figure 14 (a) Synthesis of complex 2 (Z-DMC-OXA). (b) Preparation of polymer-Z-DMCOXA conjugate and micelles. (c) Dual action modes upon cancer cells of polymer-Z-DMCOXA conjugate. Reprinted with permission from Ref. [152]. Copyright 2014, WILEY-VCH Verlag GmbH \& Co. KGaA, Weinheim. 
effects are expected from the use of co-delivery systems [93]. The occurrence, development, and metastasis of tumors are closely related to the cell cycle. The cell cycle is regulated by a variety of factors, and these factors are mutually associated and constrained. Most chemotherapeutic drugs affect cells in the replication cycle. Therefore, the cell cycle regulator combined with chemotherapeutic drugs is an anticancer strategy with huge application potential. These regulatory factors can regulate the cell cycle, block cells in a certain cycle, or promote cell cycle progression. Cell cycle regulators combined with chemotherapeutic drugs can increase the sensitivity of cancer cells to chemotherapeutic drugs, reduce the resistance of cells to chemotherapeutic drugs, and improve the treatment efficiency. The regulatory factors that promote cell cycle progression are mainly acting on cancer cells in the G0 phase, which can promote their entry into the cell cycle, make them sensitive to CCSA drugs, increase the tumor killing ratio, and further inhibit the recurrence of cancer. On the other hand, while the cell cycle checkpoint is abolished, the cells damaged by chemotherapeutic drugs are too late to repair the damage and enter the next cell cycle, thereby inducing apoptosis.

Most of the current research is focused on inhibiting or blocking cell cycle progression. There is insufficient research on the combination of cell cycle regulators and chemotherapeutic drugs, especially the factors that can promote the progress of the cell cycle. The current clinical treatment of solid tumors is mostly operated by using radiation or surgery to shrink or remove the tumor firstly, and the remaining cancer cells are cleared by chemotherapy. There is the possibility that the dormant cells inside the tumor are stimulated by surgery or radiotherapy to re-enter the replication phase, which can be effectively killed further by cell cycle-specific chemotherapy drugs [156]. Using chemotherapy in combination with cell cycle regulation strategies to achieve a clinically similar effect on tumors in a reasonable implementation method would avoid the side effects and pain associated with radiation therapy and surgery. Note that the dosage of cell cycle regulation agents should be precise and wellcontrolled.

At present, some malignant tumors are difficult to eradicate in clinical practice, and these residual cancer cells have stronger invasive ability and are easier to metastasize and relapse. Some cancer cells that evade senescence may gain stemness capacity through genetic reprogramming, thereby having stronger replication and invasion capabilities [157]. In fact, regulating the cell cycle to treat tumors does not necessarily mean annihilating all tumor cells. Tumor dormancy therapy has been proposed in academia [158]. It may be a good choice to stabilize G0 cells or induce cells to enter the dormant phase during cancer therapy. The concept is aimed at stabilizing the condition of cancer patients and enabling them to live with the dormant tumor, just like treating diabetes. Excruciating pain and side effects would be alleviated.

There are currently a large number of articles studying how to overcome various barriers by using co-delivery systems to deliver drugs with ideal efficiency $[159,160]$. Precise drug loading and controlled release of drugs targeting the complex microenvironment of tumors are the research directions of co-delivery systems. By utilizing nanotechnology, precise and efficient collaborative treatment of the chemotherapy and cell cycle regulation strategy would be achieved. This has significant implications for the design of drug delivery system and tumor treatment strategies.

Received 7 December 2020; accepted 29 January 2021; published online 27 April 2021

1 Randrian V, Biau J, Benoît C, et al. Radiothérapie avec modulation d'intensité préopératoire des cancers rectaux: Intérêt et application. Cancer/Radiothérapie, 2020, 24: 345-353

2 Kumari P, Ghosh B, Biswas S. Nanocarriers for cancer-targeted drug delivery. J Drug Targeting, 2016, 24: 179-191

3 Liu YL, Chen D, Shang P, et al. A review of magnet systems for targeted drug delivery. J Control Release, 2019, 302: 90-104

4 Abdelaziz HM, Gaber M, Abd-Elwakil MM, et al. Inhalable particulate drug delivery systems for lung cancer therapy: Nanoparticles, microparticles, nanocomposites and nanoaggregates. J Control Release, 2018, 269: 374-392

5 Qin T, Xu X, Zhang Z, et al. Paclitaxel/sunitinib-loaded micelles promote an antitumor response in vitro through synergistic immunogenic cell death for triple-negative breast cancer. Nanotechnology, 2020, 31: 365101

6 Levit SL, Yang H, Tang C. Rapid self-assembly of polymer nanoparticles for synergistic codelivery of paclitaxel and lapatinib via flash nanoprecipitation. Nanomaterials, 2020, 10: 561

7 Xiong Y, Zhao Y, Miao L, et al. Co-delivery of polymeric metformin and cisplatin by self-assembled core-membrane nanoparticles to treat non-small cell lung cancer. J Control Release, 2016, 244: 63-73

8 Rozengurt E. Autocrine loops, signal transduction, and cell cycle abnormalities in the molecular biology of lung cancer. Curr Opin Oncology, 1999, 11: 116-122

9 Ocio EM, Richardson PG, Rajkumar SV, et al. New drugs and novel mechanisms of action in multiple myeloma in 2013: A report from the international myeloma working group (IMWG). Leukemia, 2014, 28: 525-542

10 Zhang X, Xia Q, Wei R, et al. Melatonin protects spermatogonia from the stress of chemotherapy and oxidation via eliminating reactive oxidative species. Free Radical Biol Med, 2019, 137: 74- 
86

11 Ferraro G, Loreto D, Merlino A. Interaction of platinum-based drugs with proteins: An overview of representative crystallographic studies. Curr Topics Med Chem, 2021, 21: 6-27

12 Zhou SF, Wang LL, Di YM, et al. Substrates and inhibitors of human multidrug resistance associated proteins and the implications in drug development. Curr Med Chem, 2008, 15: 19812039

13 Yang L, Wang B, Qiao W, et al. A novel combination chemotherapy integrating with intratumoral chemotherapy. Med Hypotheses, 2009, 73: 334-335

14 Sarraf CE, Ansari TW, Conway P, et al. Bromodeoxyuridinelabelled apoptosis after treatment with antimetabolites in two murine tumours and in small intestinal crypts. Br J Cancer, 1993, 68: $678-680$

15 Wang X, Tanaka M, Krstin S, et al. The interference of selected cytotoxic alkaloids with the cytoskeleton: An insight into their modes of action. Molecules, 2016, 21: 906

16 Meng QY, Cong $\mathrm{HL}, \mathrm{Hu} \mathrm{H}$, et al. Rational design and latest advances of codelivery systems for cancer therapy. Mater Today Bio, 2020, 7: 100056

17 Xin ZH, Meng YL, Jiang WJ, et al. Finding an efficient tetramethylated hydroxydiethylene of resveratrol analogue for potential anticancer agent. BMC Chem, 2020, 14: 13

$18 \mathrm{Yu} \mathrm{X,} \mathrm{Li} \mathrm{S.} \mathrm{Non-metabolic} \mathrm{functions} \mathrm{of} \mathrm{glycolytic} \mathrm{enzymes} \mathrm{in}$ tumorigenesis. Oncogene, 2017, 36: 2629-2636

19 Kunnumakkara AB, Bordoloi D, Harsha C, et al. Curcumin mediates anticancer effects by modulating multiple cell signaling pathways. Clin Sci, 2017, 131: 1781-1799

20 Concato VM, Tomiotto-Pellissier F, Silva TF, et al. 3,3',5,5'-tetramethoxybiphenyl-4,4'-diol induces cell cycle arrest in G2/M phase and apoptosis in human non-small cell lung cancer A549 cells. Chemico-Biol Interact, 2020, 326: 109133

21 Zhang F, Zhang YY, Sun YS, et al. Asparanin A from Asparagus officinalis L. induces G0/G1 cell cycle arrest and apoptosis in human endometrial carcinoma Ishikawa cells via mitochondrial and PI3K/AKT signaling pathways. J Agric Food Chem, 2020, 68: 213-224

22 Vessella RL, Pantel K, Mohla S. Tumor cell dormancy: An NCI workshop report. Cancer Biol Ther, 2007, 6: 1492-1500

23 Zhou Y, Liu Q, Dai X, et al. Transdifferentiation of type II alveolar epithelial cells induces reactivation of dormant tumor cells by enhancing TGF- $\beta 1 /$ SNAI2 signaling. Oncol Rep, 2018, 39: 1874-1882

24 Nie J, Liu L, Zheng W, et al. MicroRNA-365, down-regulated in colon cancer, inhibits cell cycle progression and promotes apoptosis of colon cancer cells by probably targeting cyclin D1 and Bcl-2. Carcinogenesis, 2012, 33: 220-225

25 Xia X, Yu Y, Zhang L, et al. Inhibitor of DNA binding 1 regulates cell cycle progression of endothelial progenitor cells through induction of Wnt2 expression. Mol Med Rep, 2016, 14: 2016-2024

26 Zhu D, Yuan Y, Qiao J, et al. Enhanced anticancer activity of a protein phosphatase $2 \mathrm{~A}$ inhibitor on chemotherapy and radiation in head and neck squamous cell carcinoma. Cancer Lett, 2015, 356: 773-780

27 de Jong Y, Bennani F, van Oosterwijk JG, et al. A screening-based approach identifies cell cycle regulators AURKA, CHK1 and PLK1 as targetable regulators of chondrosarcoma cell survival. J Bone Oncol, 2019, 19: 100268

28 Diaz-Moralli S, Tarrado-Castellarnau M, Miranda A, et al. Tar- geting cell cycle regulation in cancer therapy. Pharmacol Therapeut, 2013, 138: 255-271

29 Lim S, Kaldis P. Cdks, cyclins and CKIs: Roles beyond cell cycle regulation. Development, 2013, 140: 3079-3093

30 Qie S, Diehl JA. Cyclin D1, cancer progression, and opportunities in cancer treatment. J Mol Med, 2016, 94: 1313-1326

31 Murray AW. Recycling the cell cycle. Cell, 2004, 116: 221-234

32 Elledge SJ. Cell cycle checkpoints: Preventing an identity crisis. Science, 1996, 274: 1664-1672

33 Sancar A, Lindsey-Boltz LA, Unsal-Kaçmaz K, et al. Molecular mechanisms of mammalian DNA repair and the DNA damage checkpoints. Annu Rev Biochem, 2004, 73: 39-85

34 Roos WP, Kaina B. DNA damage-induced cell death by apoptosis. Trends Mol Med, 2006, 12: 440-450

35 Khan $\mathrm{H}$, Reale $\mathrm{M}$, Ullah $\mathrm{H}$, et al. Anti-cancer effects of polyphenols via targeting p53 signaling pathway: Updates and future directions. Biotech Adv, 2020, 38: 107385

36 Guille A, Chaffanet M, Birnbaum D. Signaling pathway switch in breast cancer. Cancer Cell Int, 2013, 13: 66

37 Wu Y, Ma J, Sun Y, et al. Effect and mechanism of PI3K/AKT/ mTOR signaling pathway in the apoptosis of GC-1 cells induced by nickel nanoparticles. Chemosphere, 2020, 255: 126913

$38 \mathrm{Yu}$ Q, Zeng KW, Ma XL, et al. Resokaempferol-mediated antiinflammatory effects on activated macrophages via the inhibition of JAK2/STAT3, NF- $\kappa \mathrm{B}$ and JNK/p38 MAPK signaling pathways. Int Immunopharmacol, 2016, 38: 104-114

39 O'Shea JJ, Schwartz DM, Villarino AV, et al. The JAK-STAT pathway: Impact on human disease and therapeutic intervention. Annu Rev Med, 2015, 66: 311-328

40 Huang L, Shan YJ, He CX, et al. Effects of L. paracasei subp. paracasei X12 on cell cycle of colon cancer HT-29 cells and regulation of mTOR signalling pathway. J Funct Foods, 2016, 21: 431-439

41 Elliott B, Millena AC, Matyunina L, et al. Essential role of jund in cell proliferation is mediated via Myc signaling in prostate cancer cells. Cancer Lett, 2019, 448: 155-167

42 Moloney JN, Cotter TG. ROS signalling in the biology of cancer. Seminars Cell Dev Biol, 2018, 80: 50-64

43 Felty Q, Singh KP, Roy D. Estrogen-induced G1/S transition of G0-arrested estrogen-dependent breast cancer cells is regulated by mitochondrial oxidant signaling. Oncogene, 2005, 24: 4883-4893

44 Liou GY, Storz P. Reactive oxygen species in cancer. Free Radical Res, 2010, 44: 479-496

45 Marsh JC. The effects of cancer chemotherapeutic agents on normal hematopoietic precursor cells: A review. Cancer Res, 1976, 36: 1853-1882

46 Cao R, Peng W, Wang Z, et al. $\beta$-Carboline alkaloids: Biochemical and pharmacological functions. Curr Med Chem, 2007, 14: 479500

47 Fu D, Calvo JA, Samson LD. Balancing repair and tolerance of DNA damage caused by alkylating agents. Nat Rev Cancer, 2012, 12: $104-120$

48 Khoury A, Deo KM, Aldrich-Wright JR. Recent advances in platinum-based chemotherapeutics that exhibit inhibitory and targeted mechanisms of action. J Inorg Biochem, 2020, 207: 111070

49 Ataei S, Yilmaz S, Ertan-Bolelli T, et al. Generated 3D-common feature hypotheses using the hiphop method for developing new topoisomerase I inhibitors. Arch Pharm Chem Life Sci, 2015, 348: 498-507 
50 Coussy F, El-Botty R, Château-Joubert S, et al. BrCAness, SLFN11, and RB1 loss predict response to topoisomerase I inhibitors in triple-negative breast cancers. Sci Transl Med, 2020, 12: eaax 2625

51 Kim GM, Kim YS, Ae Kang Y, et al. Efficacy and toxicity of belotecan for relapsed or refractory small cell lung cancer patients. J Thorac Oncol, 2012, 7: 731-736

52 Pommier Y. Topoisomerase I inhibitors: Camptothecins and beyond. Nat Rev Cancer, 2006, 6: 789-802

53 Ma P, Xiao H, Yu C, et al. Enhanced cisplatin chemotherapy by iron oxide nanocarrier-mediated generation of highly toxic reactive oxygen species. Nano Lett, 2017, 17: 928-937

54 Noh J, Kwon B, Han E, et al. Amplification of oxidative stress by a dual stimuli-responsive hybrid drug enhances cancer cell death. Nat Commun, 2015, 6: 6907

55 Costi MP, Tondi D, Rinaldi M, et al. Structure-based studies on species-specific inhibition of thymidylate synthase. Biochim Biophys Acta (BBA)-Mol Basis Dis, 2002, 1587: 206-214

56 Longley DB, Harkin DP, Johnston PG. 5-Fluorouracil: Mechanisms of action and clinical strategies. Nat Rev Cancer, 2003, 3: 330-338

57 Adjei AA. Pemetrexed (ALIMTA), a novel multitargeted antineoplastic agent. Clin Cancer Res, 2004, 10: 4276s-4280s

58 Abali EE, Skacel NE, Celikkaya $\mathrm{H}$, et al. Regulation of human dihydrofolate reductase activity and expression. Vitam Horm, 2008, 79: 267

59 Raimondi MV, Randazzo O, La Franca M, et al. DHFR inhibitors: Reading the past for discovering novel anticancer agents. Molecules, 2019, 24: 1140

60 Zhang L, Guo J, Jiang XM, et al. Identification of nagilactone $\mathrm{E}$ as a protein synthesis inhibitor with anticancer activity. Acta Pharmacol Sin, 2020, 41: 698-705

61 Ferreira R, Schneekloth Jr. JS, Panov KI, et al. Targeting the RNA polymerase I transcription for cancer therapy comes of age. Cells, 2020, 9: 266

62 Chand S, Mahajan RV, Prasad JP, et al. A comprehensive review on microbial $L$-asparaginase: Bioprocessing, characterization, and industrial applications. Biotech Appl Biochem, 2020, 67: 619-647

63 Battogtokh G, Choi YS, Kang DS, et al. Mitochondria-targeting drug conjugates for cytotoxic, anti-oxidizing and sensing purposes: Current strategies and future perspectives. Acta Pharm Sin B, 2018, 8: 862-880

64 Mordente A, Meucci E, Silvestrini A, et al. Anthracyclines and mitochondria. Adv Exp Med Biol, 2012, 942: 385-419

65 Gilles A, Frechin L, Natchiar K, et al. Targeting the human 80s ribosome in cancer: From structure to function and drug design for innovative adjuvant therapeutic strategies. Cells, 2020, 9: 629

66 Burger K, Mühl B, Harasim T, et al. Chemotherapeutic drugs inhibit ribosome biogenesis at various levels. J Biol Chem, 2010, 285: 12416-12425

67 Al-Wadei HAN, Al-Wadei MH, Ullah MF, et al. Celecoxib and GABA cooperatively prevent the progression of pancreatic cancer in vitro and in xenograft models of stress-free and stress-exposed mice. PLoS ONE, 2012, 7: e43376

68 Hsu AL, Ching TT, Wang DS, et al. The cyclooxygenase-2 inhibitor celecoxib induces apoptosis by blocking Akt activation in human prostate cancer cells independently of Bcl-2. J Biol Chem, 2000, 275: 11397-11403

69 Fukunaga T, Nagahama M, Hatsuzawa K, et al. Implication of sphingolipid metabolism in the stability of the golgi apparatus. J
Cell Sci, 2000, 113: 3299-3307

70 Crespo I, San-Miguel B, Prause C, et al. Glutamine treatment attenuates endoplasmic reticulum stress and apoptosis in TNBSinduced colitis. PLoS ONE, 2012, 7: e50407

71 Peng C, Zhao Y, Hao Y, et al. Syk expression in non-small-cell lung cancer and its relation with angiogenesis. J Can Res Ther, 2016, 12: 663-666

72 Ye W. The complexity of translating anti-angiogenesis therapy from basic science to the clinic. Dev Cell, 2016, 37: 114-125

73 Ferrara N, Kerbel RS. Angiogenesis as a therapeutic target. Nature, 2005, 438: 967-974

74 Yang JI, Jin B, Kim SY, et al. Antitumour effects of liporaxel (oral paclitaxel) for canine melanoma in a mouse xenograft model. Vet Comp Oncol, 2020, 18: 152-160

75 Gao P, Wang LL, Liu J, et al. Dihydroartemisinin inhibits endothelial cell tube formation by suppression of the STAT3 signaling pathway. Life Sci, 2020, 242: 117221

76 Van der Veldt AAM, Lubberink M, Bahce I, et al. Rapid decrease in delivery of chemotherapy to tumors after anti-VEGF therapy: Implications for scheduling of anti-angiogenic drugs. Cancer Cell, 2012, 21: 82-91

77 Yang WH, Xu J, Mu JB, et al. Revision of the concept of antiangiogenesis and its applications in tumor treatment. Chronic Dis Transl Med, 2017, 3: 33-40

78 Freund E, Liedtke KR, Miebach L, et al. Identification of two kinase inhibitors with synergistic toxicity with low-dose hydrogen peroxide in colorectal cancer cells in vitro. Cancers, 2020, 12: 122

79 Sun M, He L, Fan Z, et al. Effective treatment of drug-resistant lung cancer via a nanogel capable of reactivating cisplatin and enhancing early apoptosis. Biomaterials, 2020, 257: 120252

80 Deneka AY, Einarson MB, Bennett J, et al. Synthetic lethal targeting of mitotic checkpoints in HPV-negative head and neck cancer. Cancers, 2020, 12: 306

81 Cong $\mathrm{Y}$, Xiao H, Xiong $\mathrm{H}$, et al. Dual drug backboned shattering polymeric theranostic nanomedicine for synergistic eradication of patient-derived lung cancer. Adv Mater, 2018, 30: 1706220

82 Moghaddam SV, Abedi F, Alizadeh E, et al. Lysine-embedded cellulose-based nanosystem for efficient dual-delivery of chemotherapeutics in combination cancer therapy. Carbohydr Polym, 2020, 250: 116861

83 Zhang M, Hagan Iv CT, Min Y, et al. Nanoparticle co-delivery of wortmannin and cisplatin synergistically enhances chemo-radiotherapy and reverses platinum resistance in ovarian cancer models. Biomaterials, 2018, 169: 1-10

84 Rui M, Xin Y, Li R, et al. Targeted biomimetic nanoparticles for synergistic combination chemotherapy of paclitaxel and doxorubicin. Mol Pharm, 2017, 14: 107-123

85 Li X, Diao W, Xue H, et al. Improved efficacy of doxorubicin delivery by a novel dual-ligand-modified liposome in hepatocellular carcinoma. Cancer Lett, 2020, 489: 163-173

86 Alle M, G BR, Kim TH, et al. Doxorubicin-carboxymethyl xanthan gum capped gold nanoparticles: Microwave synthesis, characterization, and anti-cancer activity. Carbohydr Polym, 2020, 229: 115511

87 Gothwal A, Khan I, Gupta U. Polymeric micelles: Recent advancements in the delivery of anticancer drugs. Pharm Res, 2016, 33: $18-39$

88 Li I, Nabet BY. Exosomes in the tumor microenvironment as mediators of cancer therapy resistance. Mol Cancer, 2019, 18: 32

89 Liang Y, Zhao X, Ma PX, et al. pH-responsive injectable hydro- 
gels with mucosal adhesiveness based on chitosan-grafteddihydrocaffeic acid and oxidized pullulan for localized drug delivery. J Colloid Interface Sci, 2019, 536: 224-234

90 Nosrati H, Adinehvand R, Manjili HK, et al. Synthesis, characterization, and kinetic release study of methotrexate loaded mPEG-PCL polymersomes for inhibition of MCF-7 breast cancer cell line. Pharm Dev Tech, 2019, 24: 89-98

91 Qian Q, Zhu L, Zhu X, et al. Drug-polymer hybrid macromolecular engineering: Degradable PEG integrated by platinum (IV) for cancer therapy. Matter, 2019, 1: 1618-1630

92 Meng J, Agrahari V, Youm I. Advances in targeted drug delivery approaches for the central nervous system tumors: The inspiration of nanobiotechnology. J Neuroimmune Pharmacol, 2017, 12: 84-98

93 Fumoto S, Nishida K. Co-delivery systems of multiple drugs using nanotechnology for future cancer therapy. Chem Pharm Bull, 2020, 68: 603-612

94 Kommineni N, Mahira S, Domb AJ, et al. Cabazitaxel-loaded nanocarriers for cancer therapy with reduced side effects. Pharmaceutics, 2019, 11: 141

95 Soe ZC, Kwon JB, Thapa RK, et al. Transferrin-conjugated polymeric nanoparticle for receptor-mediated delivery of doxorubicin in doxorubicin-resistant breast cancer cells. Pharmaceutics, 2019, 11: 63

96 Wang Y, Ding Y, Xu Y, et al. Mixed micelles of TPGS and Soluplus ${ }^{\circledR}$ for co-delivery of paclitaxel and fenretinide: In vitro and in vivo anticancer study. Pharm Dev Tech, 2020, 25: 865-873

97 Rawal S, Patel MM. Threatening cancer with nanoparticle aided combination oncotherapy. J Control Release, 2019, 301: 76-109

98 Qiao Y, Huang X, Nimmagadda S, et al. A robust approach to enhance tumor-selective accumulation of nanoparticles. Oncotarget, 2011, 2: 59-68

99 Allen TM, Cullis PR. Liposomal drug delivery systems: From concept to clinical applications. Adv Drug Deliver Rev, 2013, 65: $36-48$

100 Sawant RR, Torchilin VP. Challenges in development of targeted liposomal therapeutics. AAPS J, 2012, 14: 303-315

101 Zeng F, Ju RJ, Liu L, et al. Efficacy in treating lung metastasis of invasive breast cancer with functional vincristine plus dasatinib liposomes. Pharmacology, 2018, 101: 43-53

102 Li C, Han X. Melanoma cancer immunotherapy using PD- $\mathrm{L}_{1}$ siRNA and imatinib promotes cancer-immunity cycle. Pharm Res, 2020, 37: 109

103 Kumar S, Sharma AR, Sharma G, et al. PLK-1: Angel or devil for cell cycle progression. Biochim Biophys Acta (BBA)-Rev Cancer, 2016, 1865: 190-203

104 Sizek H, Hamel A, Deritei D, et al. Boolean model of growth signaling, cell cycle and apoptosis predicts the molecular mechanism of aberrant cell cycle progression driven by hyperactive PI3K. PLoS Comput Biol, 2019, 15: e1006402

105 Bulbake U, Kommineni N, Bryszewska M, et al. Cationic liposomes for co-delivery of paclitaxel and anti-PLK1 siRNA to achieve enhanced efficacy in breast cancer. J Drug Deliver Sci Tech, 2018, 48: 253-265

106 Li RJ, Ying X, Zhang Y, et al. All-trans retinoic acid stealth liposomes prevent the relapse of breast cancer arising from the cancer stem cells. J Control Release, 2011, 149: 281-291

107 Mohan A, Narayanan S, Balasubramanian G, et al. Dual drug loaded nanoliposomal chemotherapy: A promising strategy for treatment of head and neck squamous cell carcinoma. Eur J
Pharm Biopharm, 2016, 99: 73-83

108 Soe ZC, Thapa RK, Ou W, et al. Folate receptor-mediated celastrol and irinotecan combination delivery using liposomes for effective chemotherapy. Colloids Surfs B-Biointerfaces, 2018, 170: $718-728$

$109 \mathrm{Ou} \mathrm{H}, \mathrm{Li}$ J, Chen C, et al. Organic/polymer photothermal nanoagents for photoacoustic imaging and photothermal therapy in vivo. Sci China Mater, 2019, 62: 1740-1758

110 Aghebati-Maleki A, Dolati S, Ahmadi M, et al. Nanoparticles and cancer therapy: Perspectives for application of nanoparticles in the treatment of cancers. J Cell Physiol, 2020, 235: 1962-1972

111 Sun Q, Zhou Z, Qiu N, et al. Rational design of cancer nanomedicine: Nanoproperty integration and synchronization. Adv Mater, 2017, 29: 1606628

112 Qin SY, Zhang AQ, Cheng SX, et al. Drug self-delivery systems for cancer therapy. Biomaterials, 2017, 112: 234-247

113 Chen J, Yang X, Huang L, et al. Development of dual-drug-loaded stealth nanocarriers for targeted and synergistic anti-lung cancer efficacy. Drug Deliver, 2018, 25: 1932-1942

114 Rezvantalab S, Drude NI, Moraveji MK, et al. PLGA-based nanoparticles in cancer treatment. Front Pharmacol, 2018, 9: 1260

115 Khan I, Joshi G, Nakhate KT, et al. Nano-co-delivery of berberine and anticancer drug using PLGA nanoparticles: Exploration of better anticancer activity and in vivo kinetics. Pharm Res, 2019, 36: 149

116 Mohammed AFA, Higashi T, Motoyama K, et al. In vitro and in vivo co-delivery of siRNA and doxorubicin by folate-PEG-appended dendrimer/glucuronylglucosyl- $\beta$-cyclodextrin conjugate. AAPS J, 2019, 21: 54

117 Ji Y, Liu X, Li J, et al. Use of ratiometrically designed nanocarrier targeting CDK4/6 and autophagy pathways for effective pancreatic cancer treatment. Nat Commun, 2020, 11: 4249

118 Wang S, Liu X, Chen S, et al. Regulation of $\mathrm{Ca}^{2+}$ signaling for drug-resistant breast cancer therapy with mesoporous silica nanocapsule encapsulated doxorubicin/siRNA cocktail. ACS Nano, 2019, 13: 274-283

119 Chen F, Zhang H, Jiang L, et al. Enhancing the cytotoxic efficacy of combined effect of doxorubicin and cyclosporin encapsulated photoluminescent graphene dotted mesoporous nanoparticles against lung cancer cell-specific drug targeting for the nursing care of cancer patients. J Photochem Photobiol B-Biol, 2019, 198: 111578

120 Du X, Zhang T, Ma G, et al. Glucose-responsive mesoporous silica nanoparticles to generation of hydrogen peroxide for synergistic cancer starvation and chemistry therapy. Int J Nanomed, 2019, Volume 14: 2233-2251

121 Cagel M, Tesan FC, Bernabeu E, et al. Polymeric mixed micelles as nanomedicines: Achievements and perspectives. Eur J Pharm Biopharm, 2017, 113: 211-228

122 Banala VT, Urandur S, Sharma S, et al. Targeted co-delivery of the aldose reductase inhibitor epalrestat and chemotherapeutic doxorubicin via a redox-sensitive prodrug approach promotes synergistic tumor suppression. Biomater Sci, 2019, 7: 2889-2906

123 Chen Y, Zhang W, Huang Y, et al. Pluronic-based functional polymeric mixed micelles for co-delivery of doxorubicin and paclitaxel to multidrug resistant tumor. Int J Pharm, 2015, 488: 44-58

124 Debele TA, Yu LY, Yang CS, et al. pH- and GSH-sensitive hyaluronic acid-MP conjugate micelles for intracellular delivery of doxorubicin to colon cancer cells and cancer stem cells. Bioma- 
cromolecules, 2018, 19: 3725-3737

125 Han NN, Li X, Tao L, et al. Doxorubicin and rhein loaded nanomicelles attenuates multidrug resistance in human ovarian cancer. Biochem Biophys Res Commun, 2018, 498: 178-185

126 Srisa-Nga K, Mankhetkorn S, Okonogi S, et al. Delivery of superparamagnetic polymeric micelles loaded with quercetin to hepatocellular carcinoma cells. J Pharm Sci, 2019, 108: 996-1006

127 Narayanaswamy R, Torchilin VP. Hydrogels and their applications in targeted drug delivery. Molecules, 2019, 24: 603

128 Li Z, Guan J. Thermosensitive hydrogels for drug delivery. Expert Opin Drug Deliver, 2011, 8: 991-1007

129 Lv Q, He C, Quan F, et al. DOX/IL-2/IFN- $\gamma$ co-loaded thermosensitive polypeptide hydrogel for efficient melanoma treatment. Bioactive Mater, 2018, 3: 118-128

130 Karavasili C, Andreadis DA, Katsamenis OL, et al. Synergistic antitumor potency of a self-assembling peptide hydrogel for the local co-delivery of doxorubicin and curcumin in the treatment of head and neck cancer. Mol Pharm, 2019, 16: 2326-2341

$131 \mathrm{Wu} \mathrm{X}, \mathrm{Wu} \mathrm{Y}, \mathrm{Ye} \mathrm{H}$, et al. Interleukin-15 and cisplatin co-encapsulated thermosensitive polypeptide hydrogels for combined immuno-chemotherapy. J Control Release, 2017, 255: 81-93

132 Wu X, He C, Wu Y, et al. Synergistic therapeutic effects of Schiffs base cross-linked injectable hydrogels for local co-delivery of metformin and 5-fluorouracil in a mouse colon carcinoma model. Biomaterials, 2016, 75: 148-162

$133 \mathrm{Ma} \mathrm{H}, \mathrm{He} \mathrm{C}$, Cheng Y, et al. PLK1shRNA and doxorubicin coloaded thermosensitive PLGA-PEG-PLGA hydrogels for osteosarcoma treatment. Biomaterials, 2014, 35: 8723-8734

134 Liu C, Su C. Design strategies and application progress of therapeutic exosomes. Theranostics, 2019, 9: 1015-1028

135 Luan X, Sansanaphongpricha K, Myers I, et al. Engineering exosomes as refined biological nanoplatforms for drug delivery. Acta Pharmacol Sin, 2017, 38: 754-763

136 Liang G, Zhu Y, Ali DJ, et al. Engineered exosomes for targeted co-delivery of miR-21 inhibitor and chemotherapeutics to reverse drug resistance in colon cancer. J Nanobiotechnol, 2020, 18: 10

137 Sharma AK, Prasher P, Aljabali AA, et al. Emerging era of "somes": Polymersomes as versatile drug delivery carrier for cancer diagnostics and therapy. Drug Deliv Transl Res, 2020, 10: 1171-1190

138 Qin Y, Zhang Z, Huang C, et al. Folate-targeted redox-responsive polymersomes loaded with chemotherapeutic drugs and tariquidar to overcome drug resistance. j Biomed Nanotechnol, 2018, 14: 1705-1718

139 Aarts M, Linardopoulos S, Turner NC. Tumour selective targeting of cell cycle kinases for cancer treatment. Curr Opin Pharmacol, 2013, 13: 529-535

140 Huang J, Ji G, Xing L, et al. Neo-endocrinochemotherapy: A novel approach for enhancing chemotherapeutic efficacy in clinic? Med Hypotheses, 2013, 80: 441-446

141 Huang J, Jin L, Ji G, et al. Implication from thyroid function decreasing during chemotherapy in breast cancer patients: Chemosensitization role of triiodothyronine. BMC Cancer, 2013, 13: 334

142 Conzemius MG, Graham JC, Haynes JS, et al. Effects of treatment with growth hormone and somatostatin on efficacy of diammine [1,1-cyclobutane dicarboxylato (2-)-0,0']-(SP-4-2) in athymic rats with osteosarcoma. Am J Vet Res, 2000, 61: 646-650

143 Zou K, Ju JH, Xie H. Pretreatment with insulin enhances anticancer functions of 5-fluorou-racil in human esophageal and co- lonic cancer cells. Acta Pharmacol Sin, 2007, 28: 721-730

144 Ijichi K, Adachi M, Ogawa T, et al. Cell-cycle distribution and thymidilate synthatase (TS) expression correlate with 5-FU resistance in head and neck carcinoma cells. Anticancer Res, 2014, 34: 2907-2911

145 Reinhardt HC, Aslanian AS, Lees JA, et al. P53-deficient cells rely on ATM- and ATR-mediated checkpoint signaling through the p38MAPK/MK2 pathway for survival after DNA damage. Cancer Cell, 2007, 11: 175-189

146 Murrow LM, Garimella SV, Jones TL, et al. Identification of WEE1 as a potential molecular target in cancer cells by RNAi screening of the human tyrosine kinome. Breast Cancer Res Treat, 2010, 122: 347-357

147 Jin J, Fang H, Yang F, et al. Combined inhibition of ATR and WEE1 as a novel therapeutic strategy in triple-negative breast cancer. Neoplasia, 2018, 20: 478-488

148 Sen T, Della Corte CM, Milutinovic S, et al. Combination treatment of the oral CHK1 inhibitor, SRA737, and low-dose gemcitabine enhances the effect of programmed death ligand 1 blockade by modulating the immune microenvironment in SCLC. J Thorac Oncol, 2019, 14: 2152-2163

149 Riesterer O, Matsumoto F, Wang L, et al. A novel Chk inhibitor, XL-844, increases human cancer cell radiosensitivity through promotion of mitotic catastrophe. Invest New Drugs, 2011, 29: 514-522

150 Reithofer MR, Valiahdi SM, Galanski M, et al. Novel endothallcontaining platinum(IV) complexes: Synthesis, characterization, and cytotoxic activity. Chem Biodiversity, 2008, 5: 2160-2170

151 Yu CW, Li KKW, Pang SK, et al. Anticancer activity of a series of platinum complexes integrating demethylcantharidin with isomers of 1,2-diaminocyclohexane. Bioorg Med Chem Lett, 2006, 16: 1686-1691

152 Wang E, Xiong H, Zhou D, et al. Co-delivery of oxaliplatin and demethylcantharidin via a polymer-drug conjugate. Macromol Biosci, 2014, 14: 588-596

153 Zhou D, Xiao H, Meng F, et al. A polymer-(tandem drugs) conjugate for enhanced cancer treatment. Adv Healthcare Mater, 2013, 2: 822-827

154 Fan Z, Luo H, Zhou J, et al. Checkpoint kinase 1 inhibition and etoposide exhibit a strong synergistic anticancer effect on chronic myeloid leukemia cell line K562 by impairing homologous recombination DNA damage repair. Oncol Rep, 2020, 44: 21522164

155 Sanij E, Hannan K, Xuan J, et al. Inhibition of RNA polymerase I transcription activates targeted DNA damage response and enhances the efficacy of PARP inhibitors in high-grade serous ovarian cancer. Clin Cancer Res, 2020, 26: 74-75

156 Tang Xu, Gou X. Is chemotherapy the only option to treat the residual solid tumor cells at the G0 phase after inducing them into the cell cycle? Negative, 2019, 10: 26-28

157 Milanovic M, Fan DNY, Belenki D, et al. Senescence-associated reprogramming promotes cancer stemness. Nature, 2018, 553: 96-100

158 Lee JH, Koung FP, Cho CK, et al. Review of tumor dormancy therapy using traditional oriental herbal medicine. J Pharmacopuncture, 2013, 16: 12-20

159 Nam J, Son S, Park KS, et al. Cancer nanomedicine for combination cancer immunotherapy. Nat Rev Mater, 2019, 4: 398-414

160 Dai T, Ye F, Hu P, et al. A strategy for enhanced tumor targeting of photodynamic therapy based on Escherichia coli-driven drug 
delivery system. Sci China Mater, 2021, 64: 232-240

Acknowledgements This work was supported by the National Natural Science Foundation of China $(51703105,21675091$, and 21874078), Taishan Young Scholar Program of Shandong Province (tsqn20161027), the Natural Science Foundation of Shandong Province (ZR2017BEM012), the Major Science and Technology Innovation Project of Shandong Province (2018CXGC1407), the Key Research and Development Project of Shandong Province (2016GGX102028, 2016GGX102039, and 2017GGX20111), China Postdoctoral Science Foundation (2018M630752), the Postdoctoral Scientific Research Foundation of Qingdao, and the First Class Discipline Project of Shandong Province (22074072).

Author contributions Sun $\mathrm{Y}$ and $\mathrm{Hu} \mathrm{H}$ wrote the original draft; Jing $\mathrm{X}$, Meng $\mathrm{Q}$ and $\mathrm{Yu} \mathrm{B}$ provided some meaningful suggestions for the draft writing; $\mathrm{Hu} \mathrm{H}$ and Shen $\mathrm{Y}$ reviewed and revised the manuscript; Cong $\mathrm{H}$ supervised this study.

Conflict of interest The authors declare that they have no conflict of interest.

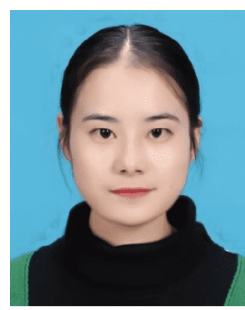

Ying Sun received her BA degree in polymer material and engineering from Qingdao University in 2019. She is pursuing her MSc degree in materials science in Prof. Cong's laboratory. Her research focuses on the combination of cell cycle regulation and chemotherapy.

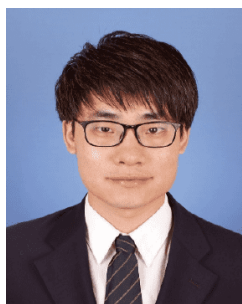

Hao Hu received his $\mathrm{PhD}$ degree from Beijing University of Chemical Technology in 2016 with Prof. Fujian Xu. In 2016, he joined the College of Materials Science and Engineering at Qingdao University as a Lecturer. His research focuses on developing smart gene/drug delivery systems for cancer therapy.

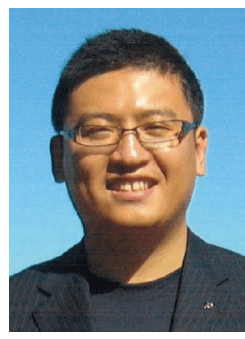

Hailin Cong received his $\mathrm{PhD}$ degree from Peking University in 2004 with Prof. Weixiao Cao. After completing a Postdoctoral Fellowship at the University of California, Davis, he joined Qingdao University in 2009 as a Distinguished Professor and Distinguished Young Scientist of Shandong Province. His current research interests lie in the synthesis and application of advanced micro-nano materials. He received The Natural Science Award from the Ministry of Education of China (2007). He has served as Member of Editorial Board of Nanoscience \& Nanotechnology since 2008 Vice Chair of Editorial Committee of China International Nanoscience and Technology Symposium since 2009, and Member of Editorial Board of Integrated Ferroelectrics since 2012.

\section{细胞周期调控与化疗共给药策略在癌症治疗中的 应用}

孙莹 $^{1 \dagger}$, 胡浩 ${ }^{1 \dagger}$, 荆晓东 ${ }^{1}$, 孟庆业 ${ }^{1}$, 于冰 ${ }^{1,2}$, 丛海林 ${ }^{1,2^{*}}$, 申有青 ${ }^{1,3}$

摘要 联合化疗是临床上用于克服肿瘤多药耐药性、提高肿瘤治 疗效果的常用策略. 然而在临床上, 传统的联合用药仍存在诸多缺 陷, 如不可避免的副作用. 纳米技术的应用和多药共同递送体系的 提出使联合治疗的治疗效果得以显著提升. 肿瘤的发生、发展和 转移与细胞周期密切相关. 因此, 在化疗过程中配合使用细胞周期 调节剂可以增强肿瘤细胞对化疗药物的敏感性. 本综述首先简要 介绍了细胞周期对肿瘤发生和发展的影响, 然后详细讨论了目前 通过多药共同递送体系结合化疗药物和细胞周期调节剂的一系列 策略. 最后, 我们总结概述了通过调控细胞周期进行肿瘤治疗的挑 战和前景 